Running head: Belief system networks and dynamics

\title{
Evaluating Belief System Networks as a Theory of Political Belief System Dynamics
}

\author{
Mark J. Brandt \\ Michigan State University Tilburg University \\ Willem W. A. Sleegers \\ Tilburg University
}

Please address correspondence to brandt15@msu.edu

Draft Date: $2021-01-13$

This paper has been accepted for publication at Personality and Social Psychology Review. It has not undergone typesetting and final proofing, which means that some things could still change.

Acknowledgements: We received helpful feedback from Felicity Turner-Zwinkels and Daniel Wisneski. This manuscript is part of a project that has received funding from the European Research Council (ERC) under the European Union's Horizon 2020 research and innovation programme (grant agreement No 759320). 


\begin{abstract}
(150 words max)
A theory of political belief system dynamics should incorporate causal connections between elements of the belief system and the possibility that belief systems are influenced by exogenous factors. These necessary components can be satisfied by conceptualizing an individual's belief system as a network of causally connected attitudes and identities which, via the interactions between the elements and the push of exogenous influences, produces the disparate phenomena in the belief systems literature. We implement this belief systems as networks theory in a dynamic Ising model and demonstrate that the theory can integrate at least six otherwise unrelated phenomenon in the political belief systems literature, including work on attitude consistency, cross-pressures, spillover effects, partisan cues, and ideological differences in attitude consensus. Our findings suggest that belief systems are not just one thing, but emerge from the interactions between the attitudes and identities in the belief system. All code is available: https://osf.io/aswy8/?view_only=2bebd3d0eabd4bc3b44fc1890bbf115e Keywords: belief systems, networks, simulation, partisanship, ideology, political psychology
\end{abstract}




\section{Evaluating Belief System Networks as a Theory of Political Belief System Dynamics}

Political belief systems are central to the study of the social sciences because they are relevant for understanding both political and non-political behavior of citizens and elites. The content of judges' belief systems impact their rulings (e.g., Zorn \& Bowie, 2010), the content of Sheriffs' belief systems influences their enforcement of immigration law (e.g., Farris \& Holman, 2017), and the content of the general publics' belief systems influences their voting decisions (Fleury \& Lewis-Beck, 1993; Jost, 2006), desire to protest (e.g., Choma, Hodson, Jagayat, \& Hoffarth, 2020), environmental concern (e.g., Cruz, 2017), and prejudice (e.g., Brandt \& Crawford, 2020), among other things. Documenting associations is important for theories of belief system content and for understanding the practical and political effects of belief system content. Our focus in this paper is on the structure of political belief systems, that is, how elements of the belief system are related (or not) for individuals. Understanding how political belief systems are structured is necessary for understanding if and how people draw on different elements of a belief system when evaluating politicians and policies (Cohen, 2003), as well as for understanding the dynamics of belief systems (e.g., Converse, 1964).

Our aim with this manuscript is to develop a theory of political belief system dynamics and to test the ability of one computational model of this theory to account for disparate phenomenon in the belief systems literature. This is a necessary task because the belief systems literature currently encompasses multiple fields, including social psychology (Jost, 2006), political psychology (e.g., Choma et al., 2020), political science (e.g., Converse, 1964), and sociology (e.g., Boutyline \& Vaisey, 2017) which leaves the field fractured. There are a variety of ostensibly independent findings without a clear idea about how those findings fit together. For example, when an attitude is manipulated it typically has weak to non-existent effects on other 
attitudes in the belief system (Coppock \& Green, in press; Hopkins \& Mummolo, 2017). At the same time, when an attitude is framed as being connected with a particular political party, people from that party are more likely to support that attitude (Bakker, Lelkes, \& Malka, 2020; Bullock, 2011; Cohen, 2003; Kam, 2005). And, at the same time, liberals in the United States tend to have more consensus in their attitudes and policy preferences than do conservatives (and conservatives have more consensus than moderates; Ondish \& Stern, 2018). These are independent findings. The papers describing the phenomenon do not cite one another. And why should they? The phenomenon do not draw on the same theoretical framework and some exist at different levels of analysis.

Here we use computational modeling to demonstrate that a theory of political belief system dynamics that conceptualizes a person's political belief system as a cognitive network of attitude and identities can parsimoniously account for these disparate phenomenon (and more). That is, by understanding the structure of the associations between political attitudes and identities, we can incorporate findings in the belief system literature and generate new predictions. Whereas, prior work on the structure of attitudes (e.g., Dalege et al., 2016; Monroe \& Reed, 2008) and the literature on attitudes more generally typically focuses on individual attitudes (Albarracin \& Vargas, 2010; Banaji \& Heiphetz, 2010; Eagly \& Chaiken, 1993), our work focuses on the structure and dynamics of multiple political attitudes and identities simultaneously. This research focus fits into what McGuire (1986) referred to as a focus on the structure within systems of attitudes. The idea with a belief system is that the state of an individual attitude is, in part, determined by its connections with other attitudes and identities (see also McGuire, 1981). We first highlight three necessary components of for any theory of 
belief system dynamics, describe how these necessities can be fulfilled with a network approach, and then specify how we implement these components in our model.

\section{Necessary Components}

There are three necessary components for any theory of political belief system dynamics.

First, the elements of the belief system need to be connected in some way for at least

some people. The very idea of a "system" implies some sort of connections between elements. A belief system is no different. This criteria of belief systems is consistent with some prior definitions of belief system (Converse, 1964) and ideology (Gerring, 1997; Jost, 2006; McGuire, 1986). These definitions describe belief systems (or ideologies) as "a configuration of ideas and attitude in which the elements are bound together" (Converse, 1964, p. 207), "a set of ideaelements that are bound together, that belong to one another in a non-random fashion (Gerring, 1997, p. 980)", or "an interrelated set of moral and political attitudes" (Jost, 2006, p. 653). The key feature across all of these definition is that belief systems consist of elements (e.g., attitudes) that are connected (see Gerring, 1997 for an exhaustive analysis of definitions of ideology). Notably, we chose the term belief systems instead of ideology because ideology is often taken to imply a more consistent, coherent, or otherwise constrained set of connections between elements (e.g., Converse, 1964; Kalmoe, 2020). From our perspective, the extent to which connections are constrained in a belief system is a feature that can (and should) be subject to empirical scrutiny, rather than a definitional necessity. Similarly, other features found in definitions of ideologies (see Gerring, 1997), such as having a clear authority or strictly logical links (amongst others) are potentially interesting influences on the belief system (e.g., Martin, 2002), rather than a necessary component for a theory of belief system dynamics. 
Second, just as any theory of belief system dynamics must include connections between elements, these connections must be causal in some way. That is, one element will influence connected elements. Although it is possible that the connections in a system are not causal (e.g., representing similarity between elements), without causal connections there cannot be belief system dynamics. Moreover, causal connections are also consistent with how scholars have understood belief systems in a dynamic sense. For example, in Converse's (1964) influential investigation of belief systems, he distinguishes between constraint, which are the connections between elements, and dynamic constraint, which is "the probability that a change in the perceived status (truth, desirability, and so forth) of one idea-element would psychologically require from, the point of view of the actor, some compensating changes(s) in the status of ideaelements elsewhere in the configuration." The causal connections between elements captures this dynamic constraint.

Third, any theory of belief system dynamics must allow for exogenous influence on the belief system. Belief systems and elements of belief systems are affected by a number of sources outside the belief system itself. That is, belief systems are not just self-contained units, but are also affected by who we are and the social world that we are embedded in. This includes (but is not limited to) possible genetic predispositions to hold particular attitudes (e.g., Dawes \& Weinschenk, 2020; Hatemi \& McDermott, 2012; Kleppestø et al., 2019), perceptions of some threats (e.g., Brandt et al., in press; Eadeh \& Chang, 2020; Jost, Stern, Rule, \& Sterling, 2017; Onraet, Dhont, \& Van Hiel, 2014), a person's place in the social hierarchy (e.g., BrownIannuzzi, Lundberg, \& McKee, 2017), and longer term influences from the culture or political context (e.g., Conway, Chan, \& Woodard, 2020). These process are likely mediated by a variety of cognitive (e.g., Zmigrod, Rentfrom, \& Robbins, 2018) and neural processes (Nam et al., 
2018). Regardless of the precise source or mechanism of such exogenous influences, a theory of belief system dynamics needs to allow for their possibility. By allowing for this possibility, it also makes it possible to make predictions about how exogenous influences and the structure of belief systems interact to produce various phenomena. In short, constraint, causality, and exogenous influence are all necessary for any theory of belief system dynamics.

\section{Belief Systems as Networks}

These three necessary components of a theory of individual belief system dynamics can be satisfied by conceptualizing belief systems as a network (see also e.g., Baldassarri \& Goldberg, 2014; Boutyline \& Vaisey, 2017; Brandt, Sibley, \& Osborne, 2019; Fishman \& Davis, in press; Homer-Dixon et al., 2013; Turner-Zwinkels et al., in press). ${ }^{1}$ An example belief system network is displayed in Figure $1 .^{2}$ In this belief systems as networks approach, the elements of a person's belief system are the nodes of the network (black dots in Figure 1). The causal connections between elements in the belief system are summarized in the edges of the network that connect the nodes (i.e. the paths in Figure 1). The exogenous influences on the belief system can influence the state of each particular node (represented by incoming arrows in Figure 1). Our approach draws inspiration from empirical investigations of belief system networks (e.g., Boutyline \& Vaisey, 2017; Brandt, Sibley, \& Osborne, 2019). There are two key differences between our approach and these prior empirical approaches. First, our approach investigates the belief systems of individuals, whereas the empirical work so far investigates belief systems as they manifest between-persons. Second, Boutylin and Vaisey’s (2017) approach was concerned

\footnotetext{
${ }^{1}$ We focus on belief systems consisting of political attitudes and identities. Other work has considered systems of belief consisting of truth statements and how they are influenced by social pressure (Friedkin et al., 2016).

${ }^{2}$ Networks in the figures were generated using the bootnet (Epskamp, Borsboom, \& Fried, 2019) and igraph (Csardi \& Nepusz, 2006) packages and are visualized using the tidyverse (Wickham et al., 2019), ggraph (Pedersen, 2020), and patchwork (Pedersen, 2019) packages in R (R Core Team, 2020).
} 
with how the belief system forms, whereas we are concerned with how belief systems change over time (for additional discussion of both of these differences see the section What Aren't We Claiming).

\section{Example Belief System Network}

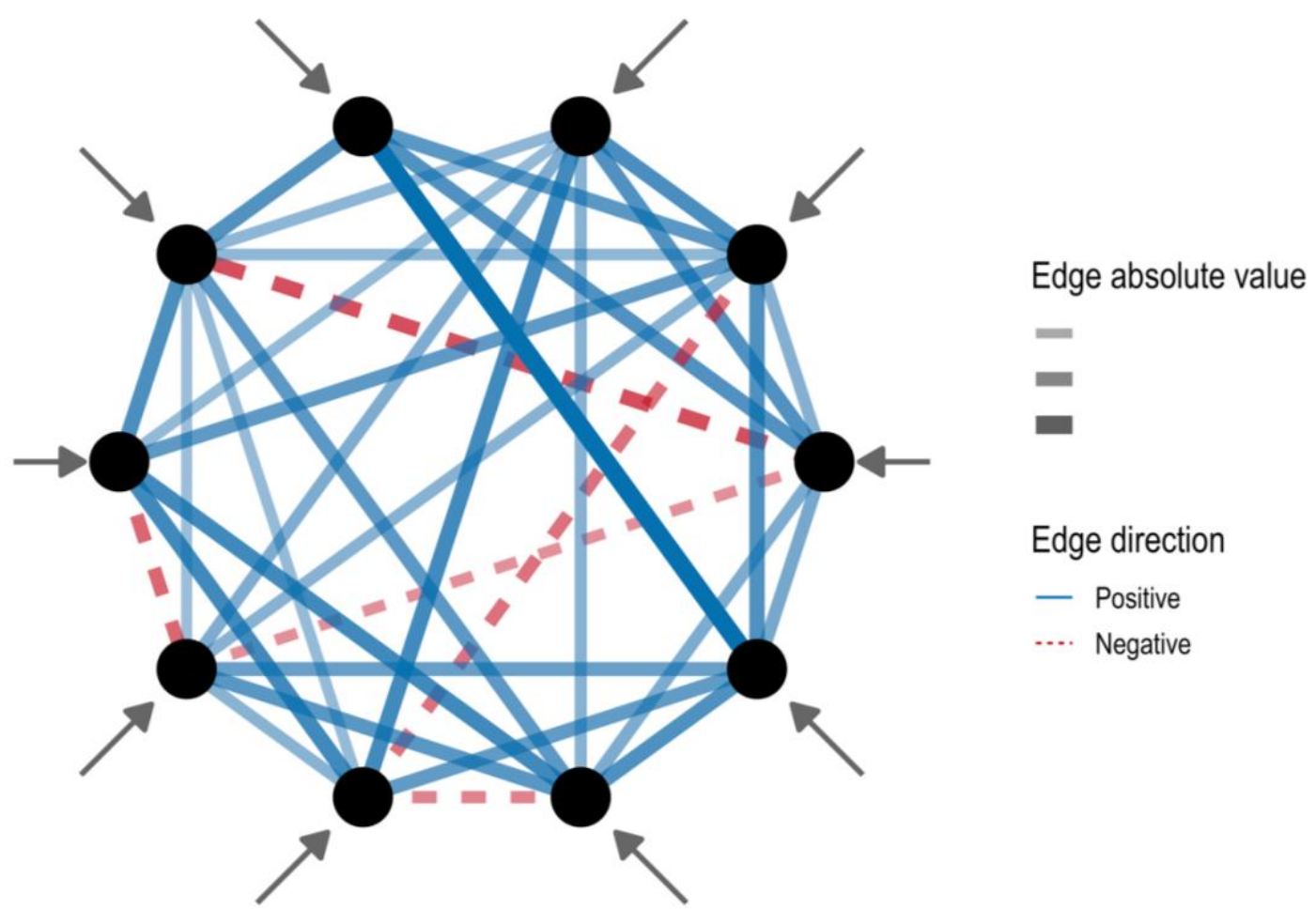

Incoming arrows represent possible exogenous influences

Figure 1. Example belief system network. Edge (i.e. path) size and opacity represent the absolute value of the edge weight (i.e. strength). Edge color and line type represent the direction (i.e. positive vs. negative) of the edge's influence. Incoming arrows represent possible exogenous influences.

The nodes of a political belief system network are politically-relevant attitudes (e.g., increased taxes on the rich, expanded abortion rights) and identities (e.g., with the Republican 
party, as a liberal). ${ }^{3}$ Although some perspectives appear to limit belief system elements to attitudes and positions on political policies (e.g., Baldassarri \& Goldberg, 2014; Kinder \& Kalmoe, 2017), the centrality of some political identities for understanding both political policy positions, political behavior, and psychology more broadly (e.g., Haas, Jones, \& Fazio, 2019; Huddy, Mason, \& Aarøe, 2015; Jost, 2006; Kinder \& Kalmoe, 2017) suggests that important information will be lost if political identities are not included in the belief system network. In the between-person empirical work on belief system networks, political identities are often more central to the belief system than are policy attitudes (Boutyline \& Vaisey, 2017; Brandt, Sibley, \& Osborne, 2019; Fishman \& Davis, in press). Politically relevant attitudes and identities map onto what others have described as components of operational ideology and symbolic ideology, respectively (Ellis \& Stimson, 2012).

The edges of a political belief system are the causal connections between the nodes. They can vary both in the strength (represented by edge thickness and opacity in Figure 1) and direction (represented by edge color and line type in Figure 1) of their influence on one another. These differences in connection strength and direction may produce different dynamics (see simulations below), but our theory does not require that the edges of any particular belief system network have a particular strength or direction of connection.

The exogenous influences on the network affects the direction of any particular node (e.g., in favor or against increased taxes on the rich, as left-wing or right-wing). The idea is that some people (e.g., Kleppestø et al., 2019), some situations (e.g., Eadeh \& Chang, 2020), or some

\footnotetext{
${ }^{3}$ The use of the term "belief" differs when discussing and theorizing about belief systems and about individual attitudes. It is important to be clear that belief systems are made up of political attitudes and identities (Converse, 1964; Gerring, 1997, Jost, 2006). In these systems, attitudes and identities are the nodes. Attitude researchers have considered how beliefs are part of attitudes, but beliefs in this context mean something different. In the context of individual attitudes, beliefs are associations between an attitude object and some other characteristic (e.g., the belief that the President is corrupt; Eagly \& Chaiken, 1993). Beliefs in the context of individual attitudes are not the focus of our work on belief systems.
} 
political contexts and institutions (e.g., Conway et al., 2020) push people in a particular direction on some attitudes and identities. All of these elective affinities (Jost, Federico, \& Napier, 2009) are summarized in the arrows in Figure 1.

There are several aspects worth clarifying further. First, it should be clarified that although Figure 1 includes ten nodes, a belief system network could contain many more nodes and might expand or contract overtime. For example, evidence from the United States suggests that the political belief system in the United States is expanding to more issues and opinions over the last decades (DellaPosta, 2020; see also work on conflict extension, Layman \& Carsey, 2002, 2010). Similarly, there are some individuals who might see fewer things as political relevant and these elements may not be incorporated into the political belief system for these individuals.

Second, it should be clarified that although we assume that the nodes are causally connected, the strength of these connections, the direction of the connections, and the mechanisms behind the connections will likely vary between people, time, and political contexts. We are agnostic about the mechanism of the causal effect that exists between nodes. For example, the effect may be due to logical connections between beliefs, a feeling of psychological fit between beliefs, the social pressure that two beliefs should be held in common, or other such mechanisms (see Converse, 1964; Goldberg \& Stein, 2018 ; Latiné, 1996; Martin, 2002 for discussions). We are also agnostic about the strength of these connections. Some work suggests that there are some people that have core political values or ideologies that organize the rest of their political attitudes (Baldassarri \& Goldberg, 2014; Converse, 1964; Kalmoe, 2020). Such people might be more likely to have a strongly connected belief system with all positive connections (Baldassarri \& Goldberg, 2014). At the same time, others will likely have a weakly connected belief system with all positive connections. Other work suggests that there is not 
consensus on the direction of the connections between policy attitudes, indicating that still others will have a belief system with some negative connections (Baldassarri \& Goldberg, 2014). The key for our theory is that the edges are the causal connections between the nodes.

Third, it should be clarified that although each node in Figure 1 only includes one arrow, this should not be taken as an indicator that each node only has one exogenous influence. Instead this should be thought of as a summary of exogenous influence across all possible exogenous influences on a particular node. Similarly, it should not be assumed that each exogenous influence necessarily only impacts one node. For example, genetic predispositions for certain political positions may exert it's influence across a range of nodes in the belief system (e.g., Friesen \& Ksiazkiewicz, 2015; Kleppestø et al., 2019).

In short, our theory is that a political belief system is a network of causally connected attitudes and identities which, via the interactions between the nodes and the push of exogenous influences, produces the disparate phenomena in the belief systems literature. This means that a belief system is not just one thing, but rather emerges from the interactions between many different things. It is largely consistent with work suggesting meaning arises from the links between individual beliefs in people's mental representations (Heine, Proulx, \& Vohs, 2006; Read, Vanman, \& Miller, 1997; Thagard, 2006).

\section{Belief System Network Implementation}

Now that we have described our theory of belief system network dynamics, the next step is to implement it in mathematical equations, computer code, and simulations (Guest \& Martin, 2020). These steps make our verbal description of the theory concrete. One challenge with verbal theories is that they can be interpreted in multiple ways and lead to, sometimes, opposing hypotheses and conclusions (Guest \& Martin, 2020; Robinaugh, Haslbeck, Ryan, Fried, \& 
Waldorp, 2020). One toy example involves pizza (as described in Guest \& Martin, 2020).

Imagine that after a long week of work, you and your friends want to order pizza. Your friends all agree on toppings and you all agree that you want to order the most pizza for the money. You could buy one large 18 " pizza or two 12 " pizzas for the same price. This is where you come to an impasse. One friend uses their verbal theory for most pizza and says that two 12 " pizzas is the right decision. Another friend uses the same verbal theory for most pizza and says that one 18" pizza is the way to go. How to decide? You turn to the well accepted mathematical model for the area of a circle. Solving this equation for both 12 " and 18 " pizzas reveals that the 18 " pizza has the most pizza for the money. By implementing the verbal theory of "buy more pizza" in a mathematical model we get different conclusions than at least one friend's verbal theory.

Although purchasing the most pizza for the money is a practically important problem, it is well worked out. The belief systems literature, on the other hand, is not. Therefore, rather than relying on our verbal theory of belief system networks we also implement our theory in mathematical equations, computer code, and simulations. This process removes our intuitions from the process of making predictions. Instead, our theory and assumptions are included in our implementation of the theory which lets us see what the outcomes of the theory are. We use our implementation to simulate belief system networks and assess how well the outcomes of these simulations map onto existing patterns of data in the literature. Sometimes the results match intuitions, but sometimes they do not (see e.g., phenomenon 4 about spillover effects).

One way to implement belief systems as networks is to use an Ising model. The Ising model is originally from statistical physics and was used to model ferromagnetism (Ising, 1925; Glauber, 1963; Kindermann \& Snell, 1980). In an Ising model, each node can take one of two states $(+1,-1)$ that can represent anything that can be in two states. When it comes to magnets, 
this is the spin of the molecule. The nodes in an Ising model are connected with one another and these connections can be positive or negative. Nodes that are positively connected with one another want to be in the same state (i.e. +1 or -1 ), whereas nodes that are negatively connected with one another want to be in opposite states. The connections can also differ in strength, such that stronger positive connections put more pressure on the nodes to share a state and stronger negative connections put more pressure on the nodes to share opposite states. This relatively simple model has been used to illuminate research areas across the sciences. ${ }^{4}$ Psychologists have borrowed from the Ising model to model the dynamics of psychopathology (Cramer et al., 2016) and the measurement of individual attitudes (Dalege et al., 2016). For example, Dalege and colleagues (2016) conceptualize individual attitudes (e.g., overall attitude towards Donald Trump) as a network of evaluations of an attitude object (e.g., untrustworthy, entertaining, etc.) and argue that attitude networks can be fruitfully described using the Ising model.

Just as Ising models can be used to conceptualize and model an individual attitude, Ising models can be used to conceptualize and model collections of interconnected individual attitudes (for a discussion of the link between attitude networks and belief system networks see section What Are Plausible Uses and Extensions?). That is, belief system dynamics. With this model in hand, we can conduct simulations that test predictions and generate explanations for phenomena in the belief systems literature. We implement a dynamic Ising model and show how the model can integrate multiple phenomenon in the belief systems literature. Although such an integration might be possible using a traditional narrative review, simulations and the mathematical models and code needed to conduct the simulations make our assumptions explicit (Guest \& Martin, 2020).

\footnotetext{
${ }^{4}$ This relatively simple model has also been used to inspire more complex models such as Hopfield nets (Hopfield, 1982) and neural network models (Gurney, 1997).
} 
In our implementation (which draws on the implementation in Haslbeck, Epskamp, Marsman, \& Waldorp, in press), each node takes on a value of 1 or -1 , reciprocally influences the nodes it is connected to, and has a tendency to be in a positive state, negative state, or in neither state. In the language of belief systems, each element of the belief system can be rightwing (1) or left-wing (-1) indicating that the person holding the belief system holds a right-wing or left-wing position on the issue or identity. Consistent with prior approaches, what is the leftwing or right-wing position will depend on what is thought to challenge vs. support the status quo and challenge vs. support inequality in a given context (Jost, Krochik, Gaucher, \& Hennes, 2009). When elements of the belief system are connected, they reciprocally influence each other, such that elements that are positively connected want to be like each other, whereas elements that are negatively connected want to be in opposite states. This is consistent with the idea that people like to have consistent attitudes and belief systems (Festinger, 1957; Gawronski et al., 2012; Homer-Dixon et al., 2013; Read, Vanman, \& Miller, 1997; Thagard, 2006). ${ }^{5}$ The connections between nodes can be positive or negative, with higher absolute values indicating a strong influence between the connected nodes. And the tendency to be in one state or another indicates an exogenous influence that pushes each element of the belief system to have a rightwing or left-wing state (e.g., due to the experience of a recession or personality's role in shaping attitudes).

To formalize this account, we use the dynamic Ising model (Haslbeck et al., in press). For each node in the belief system, we need to specify the potential it has to be in either the rightwing (1) or left-wing $(-1)$ state. These potentials are then converted into probabilities and the

\footnotetext{
${ }^{5}$ Notably, models similar to Ising models, like parallel constraint satisfaction models, have been used to model cognitive dissonance processes (e.g., Read \& Monroe, 2019; Shultz \& Lepper, 1996).
} 
nodes either change or stay the same based on these probabilities. The potential to be in the leftwing or right-wing state can be calculated using the following two equations.

$$
\begin{gathered}
\text { Potential }\left(-1_{\text {leftwing }}\right)_{i}^{t}=\exp \left(\alpha_{i}(-1)+\sum_{j=1}^{j} \beta_{i j} x_{j}^{t-1}(-1)\right) \\
\text { Potential }\left(1_{\text {rightwing }}\right)_{i}^{t}=\exp \left(\alpha_{i}(1)+\sum_{j=1}^{j} \beta_{i j} x_{j}^{t-1}(1)\right)
\end{gathered}
$$

Equations 1 and 2 calculate the potential each node $(i)$ receives from its neighbors $\left(x_{j}\right)$ at the prior time point $(t-1)$ weighted by their interconnection $\left(\beta_{i j}\right)$ and each node's own exogenous influence $\left(\alpha_{i}\right.$, possible range $\left.[-1,1]\right)$ to be in a left-wing (equation 1 ) or right-wing (equation 2 ) state. These two log potentials need to be converted to probabilities (which sum to 1). This is done by summing the two potentials and dividing each potential by that sum. This gives the probability that a node will be in a left-wing or right-wing state as in the equation below.

$$
\begin{aligned}
& \mathrm{P}\left(-1_{\text {leftwing }}, 1_{\text {rightwing }}\right)_{i}^{t} \\
& =\left\{\begin{array}{l}
-1_{\text {leftwing }}, \frac{\text { Potential }\left(-1_{\text {leftwing }}\right)_{i}^{t}}{\text { Potential }\left(-1_{\text {leftwing }}\right)_{i}^{t}+\operatorname{Potential}\left(1_{\text {rightwing }}\right)_{i}^{t}} \\
1_{\text {rightwing }}, \frac{\text { Potential }\left(1_{\text {rightwing }}\right)_{i}^{t}}{\text { PPotential }\left(-1_{\text {leftwing }}\right)_{i}^{t}+\text { Potential }\left(1_{\text {rightwing }}\right)_{i}^{t}}
\end{array}\right.
\end{aligned}
$$

Putting together these equations, whether a node takes on a right-wing or left-wing value depends on its exogenous influence $\left(\alpha_{i}\right)$, its links with the other nodes $\left(\beta_{i j}\right)$, and the state of the linked nodes $\left(x_{j}\right)$ at the prior time point $(t-1)$. When its exogenous influence is right-wing $(>$ 0 ), it will tend to take on a right-wing state (1), when its exogenous influence is left-wing $(<0)$, it 
will tend to take on a left-wing state (-1). When its connection with another node is positive (> $0)$, the nodes' values tend to align. When its connection with another node is negative $(<0)$, the nodes tend to be different. It also means that belief systems can be encoded in a weighted adjacency matrix $\left(\mathcal{W}_{i j}\right)$, where each entry encodes the weight of the link between each pair of elements in the belief system, and an array of exogenous influences the length of the number of elements in the belief system.

It is possible to further extend our implementation of belief system networks. For example, it is plausible that some nodes do not have reciprocal associations (e.g., the nodes are unidirectional), that nodes affect themselves (i.e. self-loops), or that there are multiple clusters of nodes (e.g., economic and cultural dimensions of belief systems). We discuss possible extensions in the General Discussion. We choose to use this simpler implementation because, by itself, it can account for and unite several disparate phenomena in the belief systems literature. We discuss six phenomenon that emerge at both the individual and societal level of analysis and which are typically studied using both cross-sectional and experimental methods.

\section{Phenomena 1 \& 2: Constraint Produces Consistent and Stable Attitudes}

When considering whether or not American respondents had a belief system, Converse (1964) noted that the typical citizen has low correlations (i.e., low constraint) between issue positions and tended to have unstable attitudes over time (for an update with similar conclusions see Kinder \& Kalmoe, 2017). This is because some segments of the population seem to pay little attention to politics and so construct their attitudes on the spot (Schuman \& Presser, 1980; Schwartz, 2007). There were, however, some citizens and political elites whose issue positions were more highly correlated (i.e., high constraint) and their attitudes were more stable over time. These latter people are sometimes called ideologues. Research over the last decades has shown 
that ideologues, hold issue positions and party identities consistent with their ideological identities and their beliefs and identities are consistent over time (e.g., Baldassarri \& Goldberg, 2014; Boonen, Pedersen, \& Hooghe, 2017; Converse, 1964; Kinder \& Kalmoe, 2017; Lupton, Myers, \& Thornton, 2015; Putnam, Leonardi, \& Nanetti, 1979). This may be because these ideologues spend more time thinking about political issues (Judd \& Downing, 1990; Lavine, Thomsen, \& Gonzales, 1997). In our first simulation, we test if constraint is associated with these two phenomena. That is, we test if increasing constraint in belief system networks increases the consistency of simulated participants' belief systems (i.e. increases the chances of holding all left-wing or all right-wing attitudes) and increases the stability of simulated participants attitudes over time (i.e. decreases the standard deviation of each simulated participants' overall belief system over time).

In the network approach, constraint can be thought of as network connectivity, which we operationalize as mean edge weight (for a similar approach in a different domain see Cramer et al., 2016). A more strongly connected network represents a belief system with higher levels of constraint. In prior simulations inspired by the Ising model, more strongly connected networks result in more consistency and more stability across time (Cramer et al., 2016; consistent with expectations for belief systems). Notably, this finding is essentially what has been found in research on Ising models implemented in a large number of domains (e.g., Dalege et al., 2017; Haslbeck et al., in press; Onsager, 1944). We replicate these results with our implementation to make clear the link between these prior results and the belief system networks approach we adopt. These simulations also help introduce our approach before jumping into more complex simulations. 
For all of the simulations in this paper, we implemented the specification of belief system dynamics described above in $\mathrm{R}$ ( $\mathrm{R}$ Core Team, 2020) and made the code and results available here: https://osf.io/aswy8/?view only=2bebd3d0eabd4bc3b44fc1890bbf115e. For this simulation, we simulated participants who complete a survey consisting of 10 attitudes that make up the nodes in the belief system. For each participant, we assume that they have their own idiosyncratic belief system. That is, the exact edges in the network and the strength of those edges is different for each simulated participant. Although it is likely that people within a given context share some features of a belief system (e.g., most US Americans likely have a positive association between party identification and abortion opposition, although the link will be stronger or weaker for some people; Baldassarri \& Goldberg, 2014), we simulate a new belief system structure for each simulated participant to show that the results generalize across multiple belief system structures. We operationalize belief system structure by generating a random network (Erdos \& Renyi, 1959) where the nodes have a .8 probability of being connected and populating it with weights using the method described by Yin and $\mathrm{Li}$ (2011) for generating positive definite partial correlation matrices and implemented with the package bootnet (Epskamp, Borsboom, \& Fried, 2019). In short, we estimate which edges are present using Erdos and Renyi's (1959) method. Then, we populate those edges by drawing from a uniform distribution ranging $[0.5,1.0]$. For each row in the matrix, we divide every entry except the diagonal by the sum of the absolute value of the off-diagonal entries multiplied by 1.5. Across 1000 simulated belief systems, this results in belief systems with average edge weights of 0.074 $\left(M_{S D}=0.041, M_{\text {minimum }}=0, M_{\text {maximum }}=0.136\right)$. These are relatively weakly connected belief systems. 
To operationalize differences in constraint across participants, we simulated a total of 16000 participants with 16 different connectivity multipliers (from 0.25 to 4 in steps of 0.25 ), which makes all of the edges in the network stronger (i.e., more constraint) or weaker (i.e. less constraint). ${ }^{6}$ This range allows us to assess the impact of connectivity for networks that are nearly unrelated (connectivity multiplier $=0.25$ ) all the way to those that are very strongly related (connectivity multiplier $=4$ ). To isolate the effects of connectivity from those of edge direction, all edges are positive for all participants and we set the exogenous influences to zero for all participants (i.e. the elements of the belief system were equally likely to be in a left-wing or right-wing state). This approach gives us a clean test of the idea because the evolution of the belief system is determined by its connections and not by outside influences. After initializing the simulation with random responses for the 10 attitudes for each participant, we let the belief systems evolve for 50 time points following the dynamics laid out in equations $1-3$. We summarize this in Figure 2.

To assess attitude consistency, for each time point after the initializing time point, we find the absolute value of the mean of the 10 attitudes. Because the attitudes can take on the values of -1 and 1 , the higher levels of the absolute value of the mean indicates that more of the attitudes in the belief system are in a consistent direction (e.g., more attitudes as left-wing or right-wing). The mean attitude consistency across the 50 time points is our indicator of attitude consistency. To assess belief system stability, for each time point after the initializing time point, we find the mean of the 10 attitudes. This gives us the belief system direction (e.g., as left-wing or right-wing on average). Then, we find the standard deviation of the belief system direction

\footnotetext{
${ }^{6}$ The sample size in this and subsequent simulations was set at 1000 participants for each factor of interest. In this case, we simulated 16 different connectivity multipliers and therefore simulated a total of 16000 participants.
} 
across the 50 time points for each participant. Higher scores indicate more instability of belief system direction across time.

\section{Example Testing Phenomena $1 \& 2$}

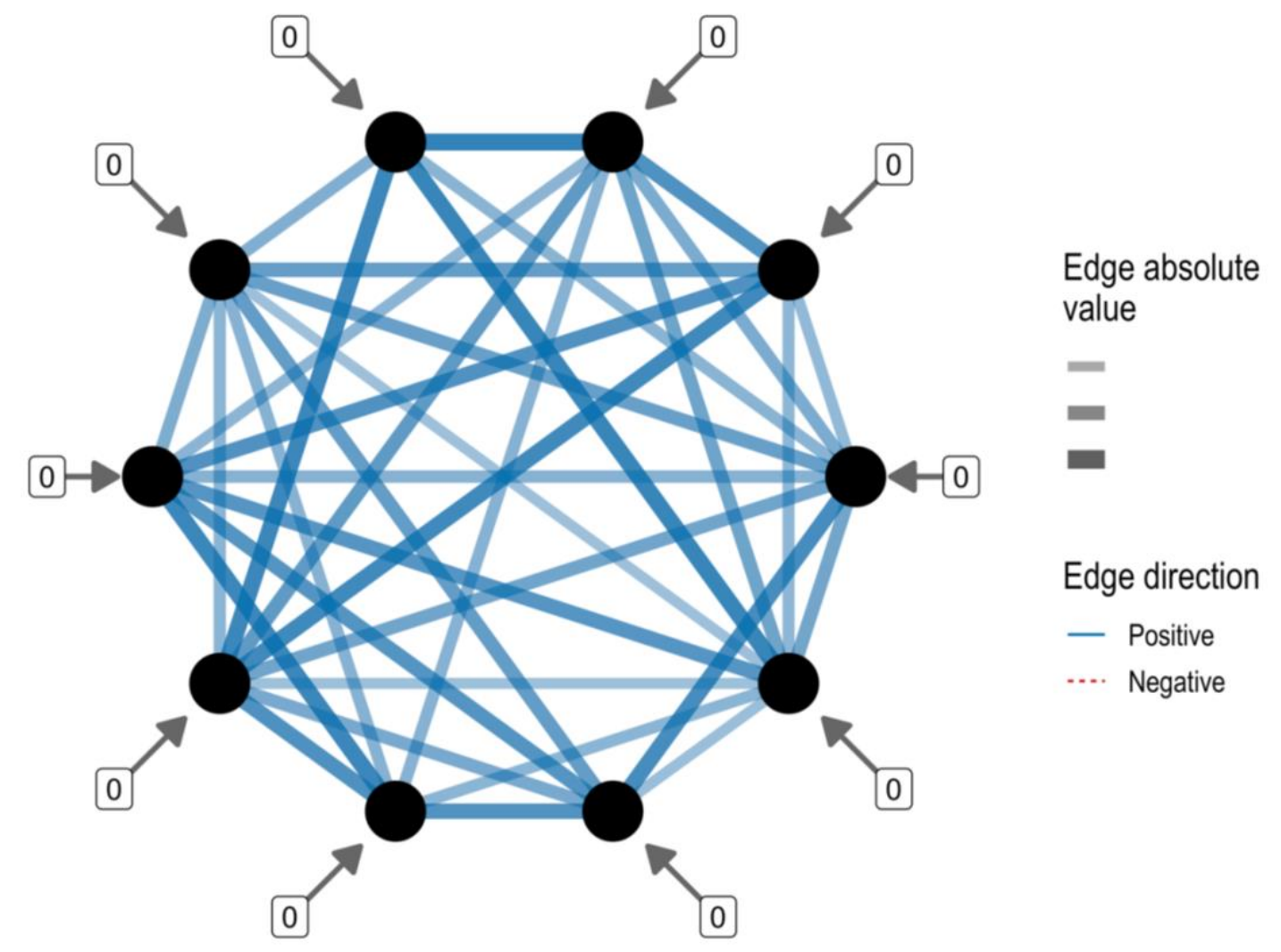

Figure 2. Example belief system networks for testing phenomenon $1 \& 2$. Edge (i.e. path) size and opacity represent the absolute value of the edge weight (i.e. strength). Edge color and line type represent the direction (i.e. positive vs. negative) of the edge's influence. For this example, all edges are positive. Incoming arrows represent possible exogenous influence. For this example, exogenous influence is set at 0 .

The results of the simulation are displayed in Figure 3. Figure 3A shows that networks with stronger connectivity multipliers (i.e., increased connectivity/constraint) have more attitude consistency. Simulated participants with more constraints are more likely to hold attitudes that are consistent with one another (e.g., all left-wing). Additionally, the results in Figure 3B show that increasing the connectivity in the network first increases the instability of the network, up 
until a certain point, after which the networks become more stable. This occurs because nodes in networks with low levels of connectivity essentially vary at random; however, with a bit of connectivity they are influenced and pushed around by other nodes, increasing the instability. At the highest levels of connectivity, the connections between nodes are strong enough that the nodes hold each other in place.

Figure $3 \mathrm{C}$ further illustrates these findings by showing the trajectories of eight random simulated participants at four levels of connectivity (two participants per level of connectivity). At lower levels of connectivity the average direction of the belief systems moves up and down across time, more or less at random. At connectivity multiplier 2, the strength of the connections is strong enough to cause reliable changes, but not yet strong enough to hold the attitudes in place. This leads to high degrees of instability; the average direction of the belief system of the two participants swings between strong left- or right-wing and moderate positions. At higher levels of connectivity the average direction of the belief system moves to be either left-wing or right-wing and then stays at these levels because the strong causal connections between individual attitudes pushes the attitude to be consistent and then holds these attitudes in place.

Taken together, these results support the notion that more strongly connected networks result in more consistency in responses and more stability across time (Converse, 1964; Kinder \& Kalmoe, 2017; Lupton, Myers, \& Thorton, 2015; Putnam, Leonardi, \& Nanetti, 1979). If thinking about political beliefs increases network connectivity (e.g., Keating \& Bergan, 2017), this may help explain the effect of such situational effects on political attitude consistency (Judd \& Downing, 1990; Lavine, Thomsen, \& Gonzales, 1997). The possibility that mid-levels of connectivity results in more instability than low levels of connectivity is a pattern that awaits testing in the belief system literature. 

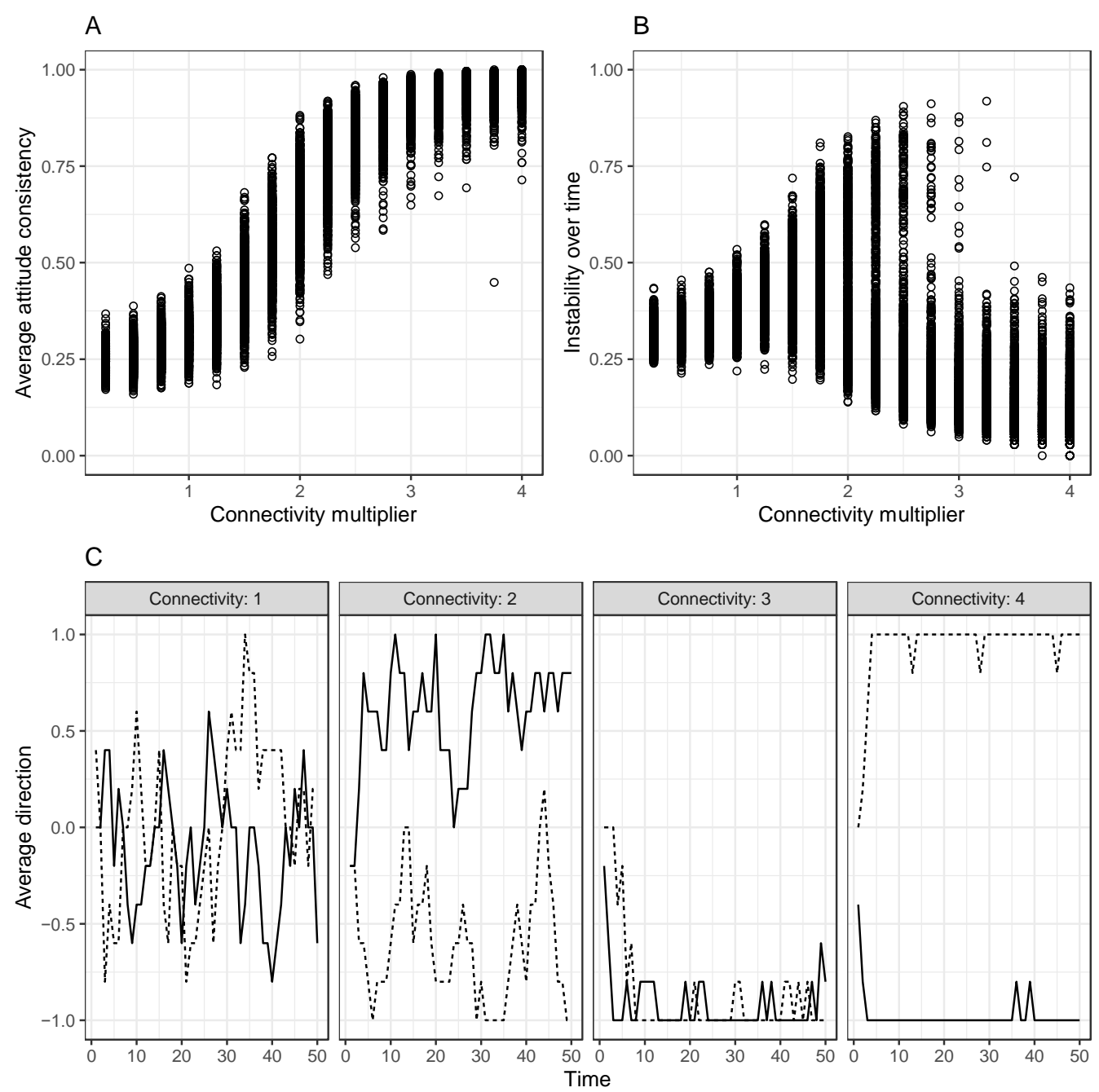

Figure 3. The relationship between network connectivity and attitude consistency (A) and stability over time (B). Each dot represents a simulated participant. Panel C contains two random simulated participants at four levels of the connectivity multiplier to illustrate the change over time.

\section{Phenomenon 3: Cross-Pressures Reduce Attitude Consistency}

Our first simulation shows that constraint produces attitude consistency and stability. Another aspect of belief systems that is associated with attitude consistency are cross-pressures, which push attitudes in opposite directions. Cross-pressures come in group-based and attitudebased forms and can both be incorporated into the network approach. These two types of crosspressures can be integrated into belief system networks in two different ways, via exogenous 
influences that push in different directions and via a mix of negative and positive edges in the structure of the belief system.

First, group-based cross-pressures occur when a person belongs to multiple demographic or social groups whose social influence and group interests push in conflicting directions (Brader, Tucker, \& Therriault, 2014; Mason, 2018). Just as people's multiple group memberships can have conflicting motivational implications (e.g., Pittinsky, Shih, \& Ambady, 1999), these multiple group memberships can have different implications for political attitudes. For example, religious Black people, poor religious people, and rich atheists are all examples of people who belong to groups that could push them in either a right-wing (e.g., religious or rich people) or left-wing (e.g., Black people or atheists) directions. Group-based cross-pressures can be incorporated into the network approach using the exogenous influences $\left(\alpha_{i}\right.$ in equations 1 and 2, the arrows in Figure 1) because these group memberships represent influences that are outside of the belief system. If groups push people to adopt right-wing positions on some attitudes, for example, this would be reflected in $\alpha_{i}>0$ on some subset of attitudes. If groups push people to adopt left-wing positions on some attitudes, this would be reflected in $\alpha_{i}<0$ on some subset of attitudes. These group influences could act on any number of exogenous influences, such as when higher socioeconomic status pushes people to be more right-wing on attitudes relevant to taxes, business regulations, and the police.

Second, attitude-based cross-pressures occur when some of a person's attitudes are negatively associated with each other (Baldassarri \& Goldberg, 2014; Campbell et al., 1960; Hillygus \& Shields, 2008). That is, their attitudes are pushed in opposite directions from different parts of their belief system. This is when the internal structure of a person's belief system indicates that two attitudes are negatively connected and want to be in opposite states (i.e. 
one right-wing and one left-wing). In the United States, this might be the case for people who have a belief system that where their positions on abortion and the death penalty are negatively linked. A person with such a negative link has the cognitive structure such that the right-wing pro-life position on abortion necessitates the left-wing position on the death penalty. Research on the structure of issue positions highlights that some subsections of the population have negative correlations between issue positions commonly thought to be positively correlated (e.g., social conservative and economic conservative beliefs; Baldassarri \& Goldberg, 2014). Attitude-based cross-pressures can be incorporated into the network approach using the direction of the edges in the network, with negative edges indicating some degree of attitude-based cross-pressure in the network.

Regardless of the type of cross-pressure, research suggests that both types of crosspressures will be associated with less attitudinal consistency. For example, some have argued that the extremity of the current Republican party is due to increasing consistency of mutually reinforcing identities, whereas the current Democratic party is less extreme, in part, because of higher levels of cross-cutting (i.e., mutually opposing) identities (Mason, 2018). Other work finds that people with cross-cutting demographic factors have more conflicting political attitudes and are less likely to be politically interested and knowledgeable (Brader, Tucker, \& Therriault, 2014; Hillygus \& Shields, 2008). We test if the different types of cross-pressures that are implemented in the belief system network in different ways result in less attitudinal consistency using two simulations.

For both of these simulations, we simulated 6000 participants. For each participant, we assume that they have their own idiosyncratic belief system and generated the belief system using the same procedure as the first simulation. For these two simulations, the connectivity 
multiplier was set at 3, a level we know from simulation 1 results in relatively stable attitudes when there are no cross-pressures.

The first simulation was set up to simulate group-based cross-pressures. We simulated networks with all positive edges where the exogenous influence on each node was set to either 0.1 or -0.1 and varied the proportion of positive and negative exogenous influences, ranging from all positive exogenous influence (i.e., no cross-pressures, all right-wing influences) to $50 \%$ positive exogenous influence (i.e., maximum cross-pressures, half left-wing influence and half right-wing influence) (see Figure 4 for an example). ${ }^{7}$ The exogenous influence represents the influence of a person's group memberships (or any exogenous influence) on the different nodes in the network, pushing different nodes in different directions. The results are shown in Figure 5A. Networks with an even split between positive (i.e. right-wing) and negative (i.e. left-wing) exogenous influences were found to produce more inconsistent attitudes than those with only positive exogenous influences. These latter networks had the most consistent attitudes. ${ }^{8}$ This simulation demonstrates how a belief system network approach can account for group-based cross pressures.

The second simulation was set up to simulate attitude-based cross-pressures. Networks were simulated that varied in the proportion of positive edges, ranging from 1 (all positive edges) to 0.5 (half positive/half negative edges; see Figure 4 for an example). The exogenous influences in this case were all set to zero. The results of the simulation are found in Figure 5B. Networks with a mix of positive and negative edges had more inconsistent attitudes than those with only

\footnotetext{
${ }^{7}$ Stronger exogenous influences produce more extreme results, whereas weaker exogenous influence produce weaker results.

${ }^{8}$ Although we present the simulation as adding left-wing exogenous influences reduces consistency, if we start with a network with all left-wing exogenous influences and add right-wing exogenous influences, networks become more inconsistent with more right-wing exogenous influence.
} 
positive edges. This simulation demonstrates how a belief system network approach can account for attitude-based cross pressures.

Together, these two simulations show that both types of cross-pressures are related to attitude inconsistency, consistent with prior work (e.g., Brader, Tucker, \& Therriault, 2014; Hillygus \& Shields, 2008). Our network approach shows how group-based and attitude-based cross-pressures are instantiated in the belief system in different ways, yet can lead to similar results (i.e. less attitude consistency).
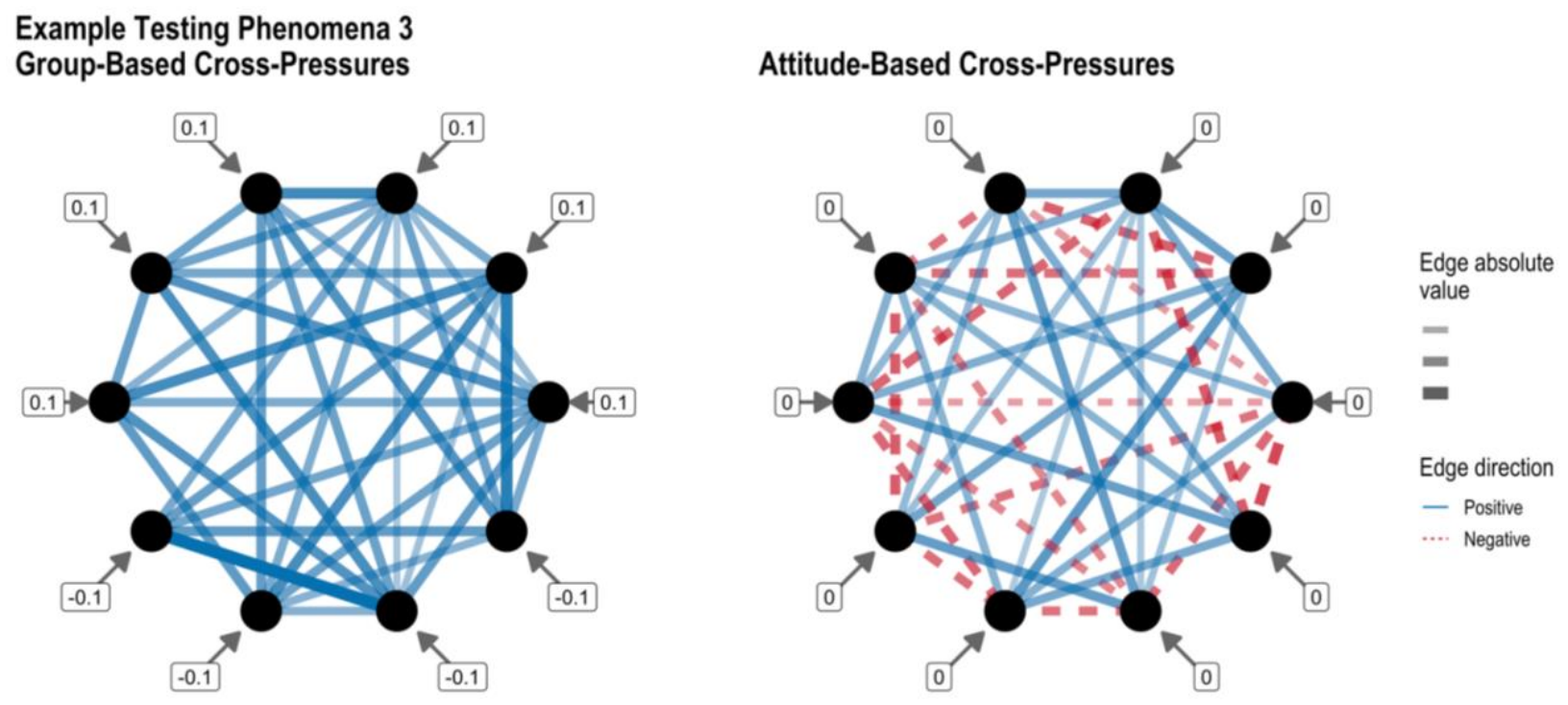

Figure 4. Example belief system networks for testing phenomenon 2. Edge (i.e. path) size and opacity represent the absolute value of the edge weight (i.e. strength). Edge color and line type represent the direction (i.e. positive vs. negative) of the edge's influence. For group-based crosspressures, all edges are positive, whereas for attitude-based cross-pressures a random proportion of edges are negative. Incoming arrows represent possible exogenous influence. For groupbased cross-pressures, exogenous influence is set to .1 and a random proportion are set to negative. For attitude-based cross-pressures, exogenous influence is set at 0 . 

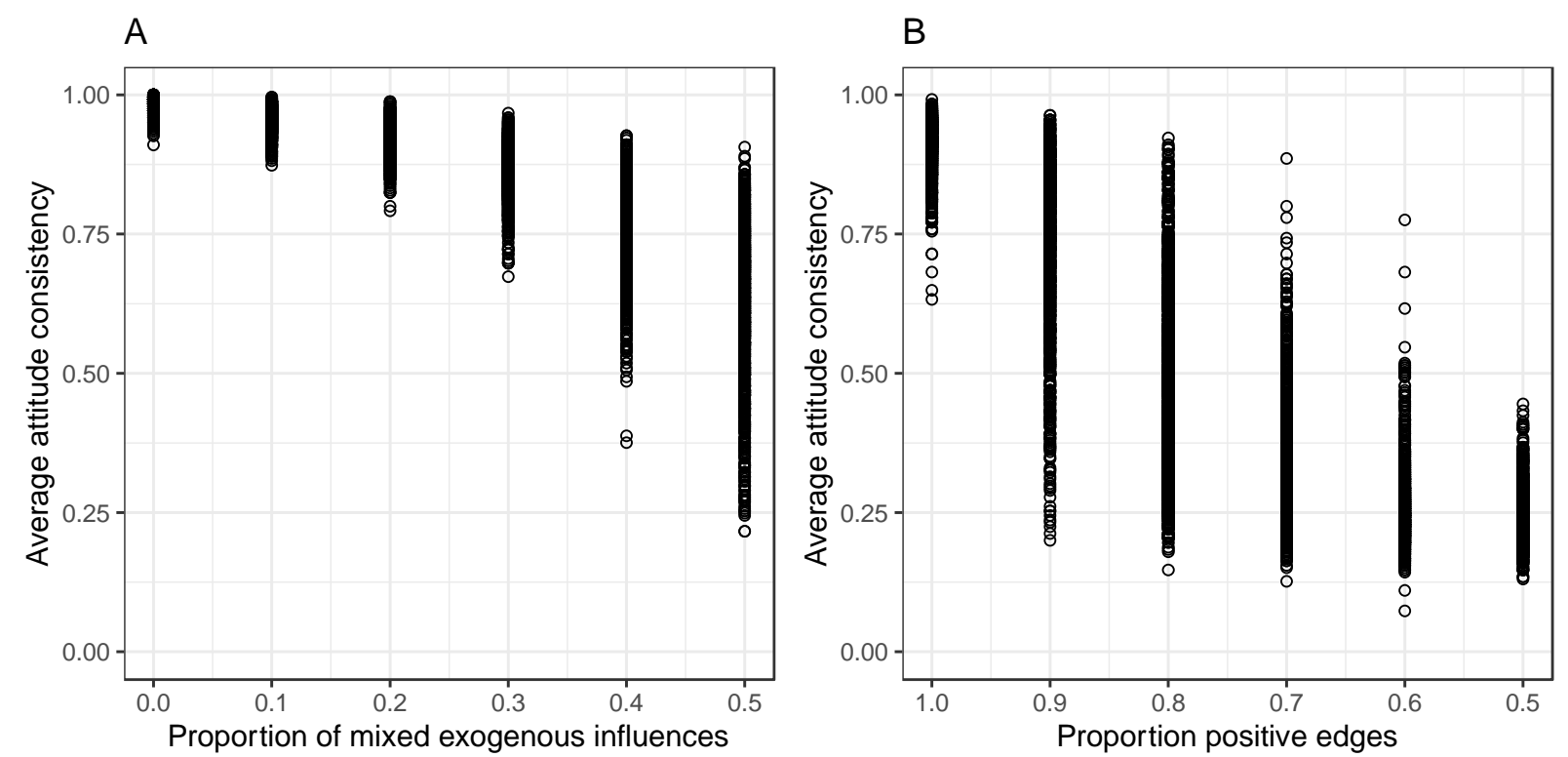

Figure 5. The relationship between the proportion of mixed endogenous influences (A) and proportion of positive edges (B) on attitude consistency. Each dot represents a simulated participant.

\section{Phenomenon 4: Spillover Effects are Rare}

One intuitive prediction when using a network approach to belief systems is that changing one belief system element will cause a detectable change on another belief system element. This is what some have called dynamic constraint (Coppock \& Green, in press). Despite the centrality of this idea to foundational work on belief systems (e.g., Converse, 1964), there have been few tests of it.

The two clearest experimental tests of these ideas manipulate participants' attitudes towards a policy using a brief persuasive or framing text. Following the manipulation, the participants complete attitudinal measures directly related to the policy (targeted attitude, e.g., funding for passenger rail service), as well as to other political policies not directly related to the targeted attitude (potential spillover attitudes, e.g., the Veterans Administration). If there is dynamic constraint, the thinking goes, then the persuasive text should not only change the targeted attitude, but also show evidence of changing the potential spillover attitudes as well. In 
one study, the spillover effects were quite small and limited (Hopkins \& Mummolo, 2017) and in the other study there were no clear spillover effects in samples of political elites and typical citizens (Coppock \& Green, in press). Together, these results have been taken as evidence that dynamic constraint does not occur and could be viewed as evidence contrary to the belief systems approach we take here. We use simulations to show that these null and weak results are consistent with the belief system network approach and to highlight factors that complicate the intuitive dynamic constraint prediction.

For example, there are other tests relevant to dynamic constraint that take advantage of more substantial experimental manipulations or experiences. Broockman and Kalla (2016) found that conversations about the rights of trans people that encouraged both active processing and perspective taking with participants at the participants' home durably reduced transphobia. A secondary outcome were attitudes about gender roles more broadly and this outcome was also affected by the manipulation. Another study took advantage of improving relations between the United States and the Soviet Union (Peffley \& Hurwitz, 1992). Using data from before and after nuclear arms summits of 1987 and 1988, this study found that people became both more dovish in their perceptions of the Soviet Union, as well as more dovish in their military policy preferences. Lastly, a study on the contact hypothesis took advantage of randomly assigned college roommates. They found that randomly assigned interracial contact reduced prejudice towards the target group (e.g., African Americans) and towards other racial out-groups (e.g., Latinos; Van Laar et al., 2005). These studies suggest that more substantial and long lasting experiences beyond reading a short persuasive text may have the impact necessary to induce some degree of dynamic constraint. 
In our implementation of the network approach, dynamic constraint is built into the model. That is, equations 1-3 specify a bidirectional causal relationship between connected elements of the belief system. So we know that dynamic constraint occurs in our model (it is the model). What we do not know is if successfully manipulating one attitude will have a detectable effect on other attitudes in the belief system and how this might vary depending on the length of the manipulation.

Although it may appear obvious that dynamic constraint should occur in our model, it is important to remember that potential spillover attitudes are not just affected by the targeted attitude (and any changes in it), but targeted attitudes are also affected by all of the other elements to which they are connected. This means that while the spillover attitudes may be influenced to be more right-wing following a brief right-wing persuasive message on the targeted attitude, the spillover attitudes may also be influenced to be more left-wing due to their connections with other attitudes in a left-wing state. Combining these probabilities does not necessarily mean that a successful and brief manipulation of the targeted attitude will result in the change of potential spillover attitudes (i.e. consistent with Coppock \& Green, in press; Hopkins \& Mummolo, 2017). ${ }^{9}$ However, a sufficiently long and impactful manipulation (e.g., living with another person, Van Laar et al., 2005) or change in experience (e.g., major world events, Peffley \& Hurwitz, 1992) may be able to induce some degree of change in potential spillover attitudes.

\footnotetext{
${ }^{9}$ Notably, Coppock and Green (in press) used several assumptions to identify several plausible directed acyclic causal graphs that would be consistent with dynamic constraint. None of these graphs assumed there were more attitudes than just the targeted attitude and the spillover attitude. None of these graphs assumed bidirectional relationships between the attitudes. We believe that additional attitudes and bidirectional relationships are plausible assumptions.
} 
Said another way, our implementation includes the necessary ingredients of dynamic constraint, including causal connections between belief system elements, yet it may not show significant spillover effects in some conditions. This would suggest that the same evidence that may be used as evidence contrary to the belief systems approach, such as those showing no clear spillover effects following brief manipulations and small changes (Coppock \& Green, in press), is in fact entirely consistent with our theory.

We tested this idea by simulating 10000 networks (i.e., participants) in a dynamic constraint experiment (e.g., like Coppock \& Green, in press). The simulation proceeded in two phases. To mimic the fact that manipulations are applied to people with existing belief systems, we first simulated networks and let them evolve over a period of 50 time points. Each network consisted of all positive edges with a probability of 0.8 for a connection. The nodes had no exogenous influences (i.e., they were all set to 0 ) and the connections were multiplied by either $0.5,1,2,3$, or 4 to vary network connectivity. Note that we use fewer multipliers here and in subsequent simulations compared to our previous simulations. This was done to reduce the duration of the simulation so that we could increase the sample size (i.e., number of networks). After the 50 time points, half of the networks were assigned to a treatment condition in which one of the nodes in the network received a manipulation by setting its exogenous influence to 0.05 (a manipulation nudging participants in a right-wing direction), while the remaining nodes kept their exogenous influence values of 0 (see Figure 6). ${ }^{10}$ Networks in both the treatment condition and the control condition then evolved for another 50 time points with these new settings. The effect of the manipulation on the targeted and potential spillover nodes was

\footnotetext{
${ }^{10}$ We chose this manipulation size because it produced reliable, but not large effects on the target attitudes. This is consistent with prior work on dynamic constraint. Stronger or weaker manipulations would likely result in different patterns, just as manipulation length produces different patterns in the simulations we report.
} 
assessed by calculating the average value of the targeted node and the average of all of the spillover nodes across three different time points: 5 time points after the manipulation (i.e., a short manipulation), 10 time points after the manipulation (medium), and 50 time points after the manipulation (long). This simulation enabled us to see whether the manipulation indeed affected the targeted node and whether there is a spillover effect. By examining the effects of the simulated manipulation on spillover nodes across different lengths of time $(5,10$, and 50$)$, we can also examine whether the change of exogenous influence simulating our manipulation has different effects depending on the duration of the manipulation. The short manipulation may be closer to a typical experimental study where people read a persuasive text and respond immediately. The longer manipulation may be closer to studies that assess the impact of long term events that exert persistent effects on an attitudes. Additionally, we also inspected whether these effects depended on the connectivity within each network. 


\section{Example Testing Phenomena 4}

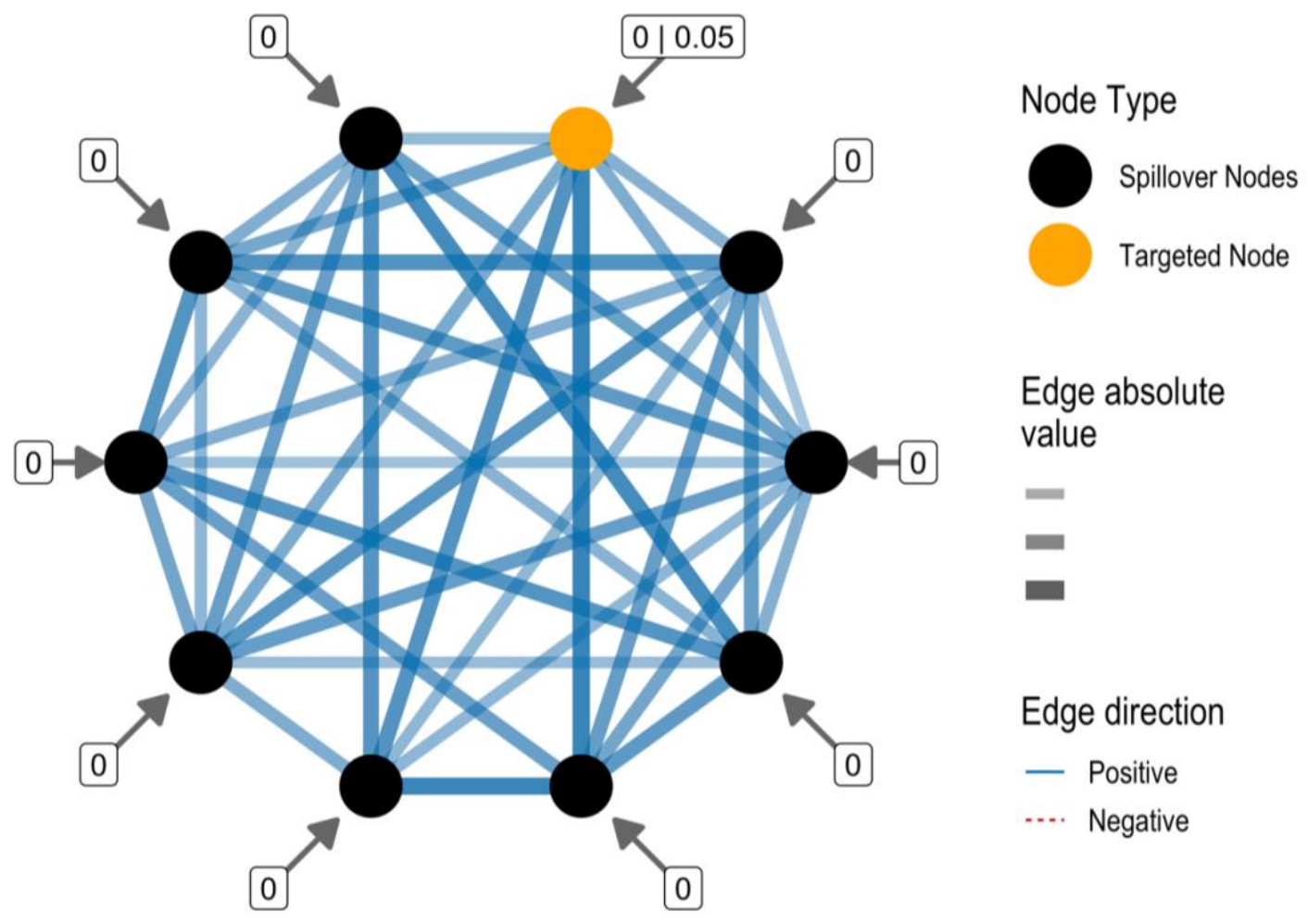

Figure 6. Example belief system networks for testing phenomenon 4. Edge (i.e. path) size and opacity represent the absolute value of the edge weight (i.e. strength). Edge color and line type represent the direction (i.e. positive vs. negative) of the edge's influence. For this example, all edges are positive. Incoming arrows represent possible exogenous influence. For this example, exogenous influence is set at 0 for all nodes for the first 50 time points. After the first 50 time points, the exogenous influence on the targeted node was randomly assigned to remain 0 (control condition) or set to 0.05 (treatment condition).

The results are displayed in Figure 7. The treatment indeed has the expected effect on the targeted node. Regardless of the duration of the manipulation, the targeted node shows a more right-wing attitude in the treatment condition compared to the control condition. This is consistent with prior work on dynamic constraint showing changes on the targeted attitude (Coppock \& Green, in press; Hopkins \& Mummolo, 2017). The results differ for the spillover nodes, where it can be seen that the treatment manipulation strongly depends on the duration of the manipulation. When the manipulation is brief, the difference of the spillover nodes between 
the treatment and control condition is much smaller than when the manipulation lasts longer. It should also be noted that the treatment effect on the spillover nodes is sizably weaker than the treatment effect on the targeted node. Even in the case of a long-lasting manipulation, the effect on the spillover node is 3.92 times weaker than the effect on the targeted node. For a brief manipulation, the treatment effect is 8.34 times weaker on the spillover nodes than it is on the targeted node. This is consistent with work finding weak and nonexistent spillover effects for brief manipulations (Coppock \& Green, in press; Hopkins \& Mummolo, 2017).

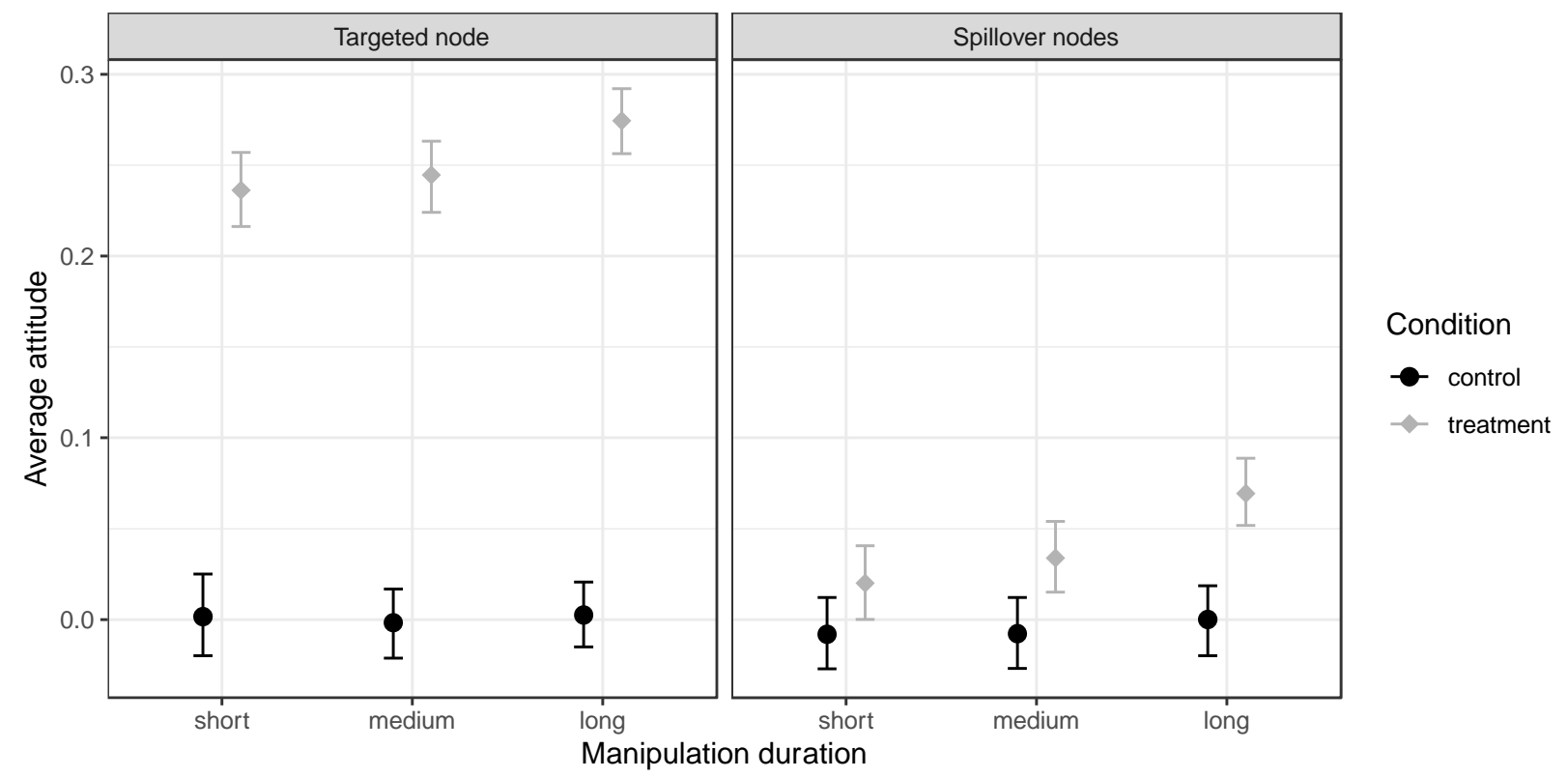

Figure 7. The effect of a treatment (e.g., attitude manipulation) on the targeted node and spillover nodes. The error bars reflect $95 \%$ confidence intervals. Note that the y-axis could range from -1 to 1 .

The effects of the treatment on the targeted node and spillover nodes are also dependent on the connectivity within each network (see Figure 8). Spillover does not occur at both higher and lower levels of connectivity. At lower levels of connectivity, the treatment causes changes on the targeted node, but these changes are not passed on to the potential spillover nodes because of the lack of meaningful connections between the nodes. At higher levels of connectivity, the 
treatment does not affect the targeted node because the targeted node is predominantly affected by the other nodes in the belief system. This unsuccessful manipulation occurred despite our knowledge that every (simulated) participant received a (simulated) manipulation of identical strength. The unsuccessful manipulation also means that there were not any spillover effects (there was nothing to spillover). This pattern of findings is reminiscent of work on attitude persuasion which found that people at moderate levels of individual differences governing susceptibility to persuasion were the most persuadable (McGuire, 1968; Rhodes \& Woods, 1992). For example, people with low levels of self-esteem are difficult to persuade because they have difficulty receiving the message, whereas people with high levels of self-esteem are difficult to persuade because they do not yield to the arguments (Rhodes \& Woods, 1992).

In summary, it is possible that there will be spillover effects in some situations and for some people. This might include after particularly strong or long lasting manipulations, or on attitudes with particularly strong direct connections with the targeted attitude. However, when we consider prior studies directly testing dynamic constraint hypotheses, neither of these conditions are satisfied. In conditions similar to existing studies (e.g., studies with brief manipulations where the underlying belief system network is unknown) our model did not clearly identify spillover effects despite embedding causal effects in the simulated model. Only for longer lasting manipulations, perhaps better mimicking in depth conversations or dramatic political events, do we observe evidence for spillover effects. But even in these cases, it is only observed for people with mid-range levels of connectivity. If people with mid-range levels of connectivity are not well represented in the population, this may further explain why prior work has such difficulty identifying spillover effects. The limited number of conditions that produce 
spillover effects suggests that empirical tests of dynamic constraint are looking for spillover effects in the wrong place.

To put a finer point on it, prior work suggesting that spillover effects are rare (Coppock \& Green, in press), use this evidence to suggest that people do not have ideologies that constrain their attitudes. That is, that dynamic constraint does not occur. In our simulations, where dynamic constraint is definitional to the model, we also rarely find spillover effects; they only emerge in certain conditions that do not appear to map onto the conditions in empirical tests. More importantly, even in the group of simulated participants who have a belief system that could be called an ideology (i.e. those with high connectivity), we do not find evidence of spillover effects. This suggests that evidence used against dynamic constraint (Coppock \& Green, in press) is actually fully consistent with our model which embeds dynamic constraint in the model. Our simulation, replicates prior work and is consistent with the phenomenon that spillover effects are rare, but also highlights those conditions under which spillover effects may be more prevalent (e.g., long term changes in target attitudes). 


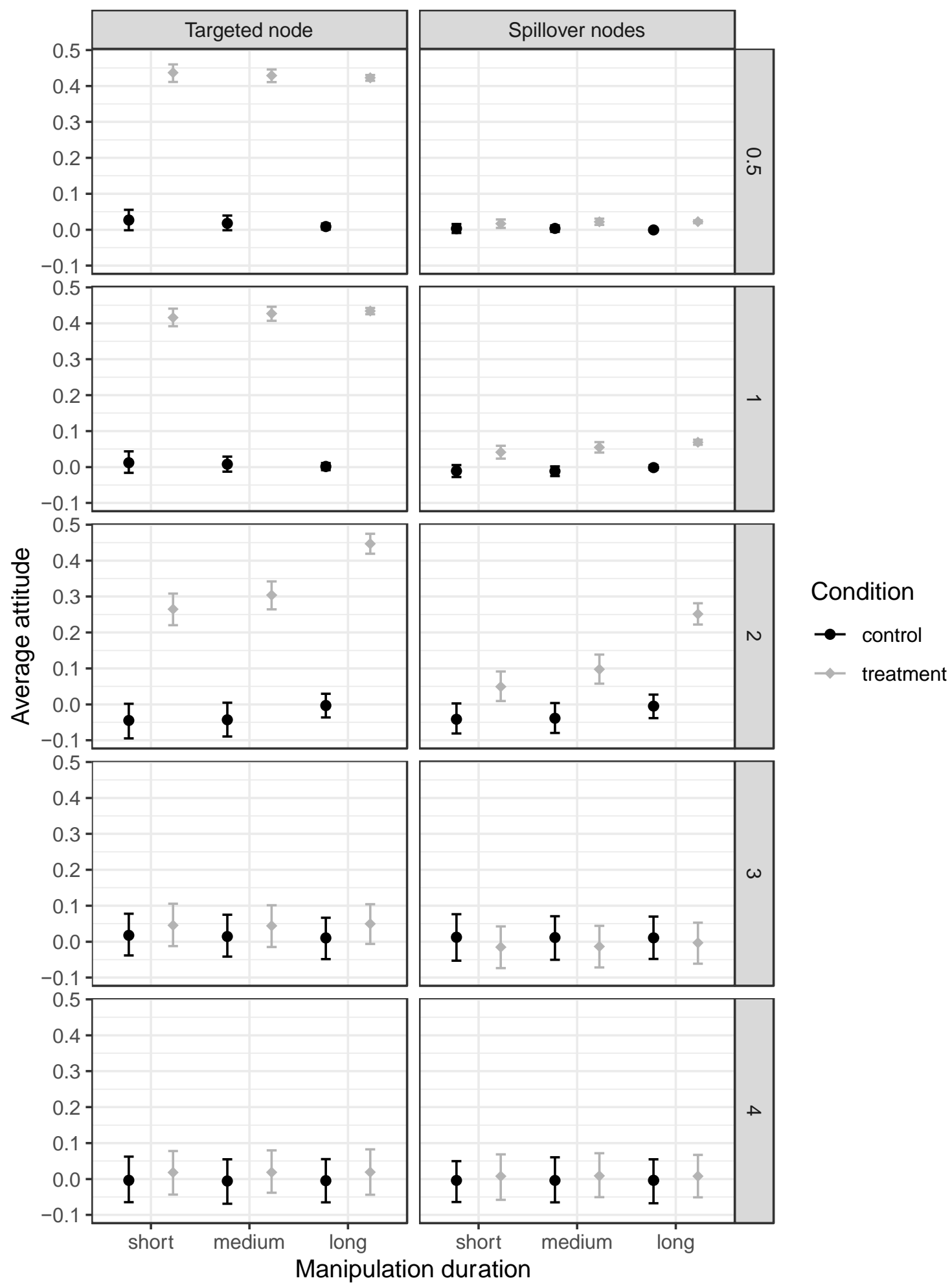

Figure 8. The effect of a treatment (e.g., attitude manipulation) on the targeted node and spillover nodes for different connectivity multipliers (rows). The error bars reflect $95 \%$ confidence intervals. Note that the $y$-axis could range from -1 to 1 . 


\section{Phenomenon 5: Partisan Cues}

Although spillover effects may be rare in practice, partisan cue experiments from multiple countries suggest that it is possible to change attitudes by connecting them to a belief system via party (Bakker et al., 2020; Bullock, 2011; Brader, De Sio, Paparo, \& Tucker, 2020; Cohen, 2003; Kam, 2005) or ideological identities (Malka \& Lelkes, 2010). In the typical partisan cue experiment, an attitude that is unrelated to partisanship (e.g., food irradiation, Kam, 2005; farm subsidies, Bakker et al., 2020) is described to participants as being supported by their in-party or an out-party. ${ }^{11}$ When the policy is described as being supported by the in-party, partisans are more likely to support the policy than when the policy is described as being supported by the out-party, perhaps as a part of broader process of maintaining ingroup identity and solidarity (e.g., Bakker et al., 2020). At the extreme, this type of phenomenon leads people to support policies that might otherwise run counter to their political values (e.g., Cohen, 2003). More generally, this experimental effect highlights the role political elites play in shaping the structure of belief systems by "helping" the general public see how political issues go together with political identities. It is also generally consistent with the findings that people interpret evidence (Washburn \& Skitka, 2018) and express prejudice (Brandt, 2017) in accordance with their political identities.

We are able to implement partisan cues in our approach by interpreting a cue as adding an edge between two elements of the belief system. In the case of right-wing-party cues, this is a positive edge that connects the node representing partisan identity to the cued attitude. In the case of left-wing-party cues, the edge is negative. In both cases, the idea is that the experimental

\footnotetext{
${ }^{11}$ It is not clear if there are theoretical reasons for this choice. Empirically, it reduces the complications of pretreatment effects (Slothuus, 2016). Pre-treatment effects could be represented in our model by connecting the targeted node with other nodes in the network. Under these situations, partisan cue simulations are closer to the spillover effect simulations, suggesting more muted effects.
} 
condition takes an attitude that is otherwise unconnected and uninfluenced by the belief system and makes it part of the belief system via its connection with partisan identity. This interpretation assumes that the cued attitude is typically unconnected with the belief system. This assumption is consistent with researchers' choice to use attitudes and policies that are not salient (Kam, 2005) and with the finding that partisanship is not associated with policy support in the neutral control conditions of partisan cue experiments (Bakker et al., 2020). This is also likely a crucial difference between the partisan cue phenomenon and tests of spillover effects. Tests of spillover effects, including the simulations above, typically focus on attitudes that are already connected with the belief system network. Partisan cue effects, however, typically start with attitudes that are either weakly connected or not connected at all to the belief system network. Then, when they are connected to the belief system network, they are primarily or only influenced by the connection with people's political identifications.

We tested the partisan cue phenomenon by simulating 3000 networks with varying properties in a partisan cue experiment (e.g., Bakker et al., 2020; Kam, 2005). Each network had one node (i.e. the party cued node) that was either connected to the belief network via a partisan identity node or entirely isolated from the network. The partisan identity node was set to be in support of a left-wing or right-wing party by setting its exogenous influence to a value ranging from -0.2 to 0.2 , in steps of 0.1 , excluding 0 (i.e. we did not simulate participants without a party identity). The belief network nodes (excluding the cued node) consisted of all positive edges with a connection probability of .8 (see Figure 9) and a connectivity multiplier of $0.5,1,2,3$, or 4. The network evolved for 50 time points to simulate the idea that people enter partisan cue experiments with an existing belief system. After the first 50 time points, the cued node was connected to the partisan identity node in the party cued conditions. The connection had a 
strength of either 0.15 (a right-wing cue) or -0.15 (a left-wing cue) plus some additional noise drawn from a normal distribution with a mean of 0 and standard deviation of 0.02 . As in prior work on this topic, we recoded the conditions to reflect in-party and out-party cues. If the connection and the exogenous influence of the partisan identity node were in the same direction (e.g., both positive or both negative) then the cued node reflected an in-party cue. If the connection and exogenous influence were in opposite directions, the cued node reflect an outparty cue. The networks then evolved for another 50 time points. Below we present the results of a brief manipulation. That is, we show the effect of the control condition, in-party cue condition, and out-party cue condition on the average value of the cued node across the first five time points following the cue. This was chosen to reflect the design of experiments in this domain, which consists of a brief manipulation (e.g., a paragraph to read) followed by questions about the cued attitude.
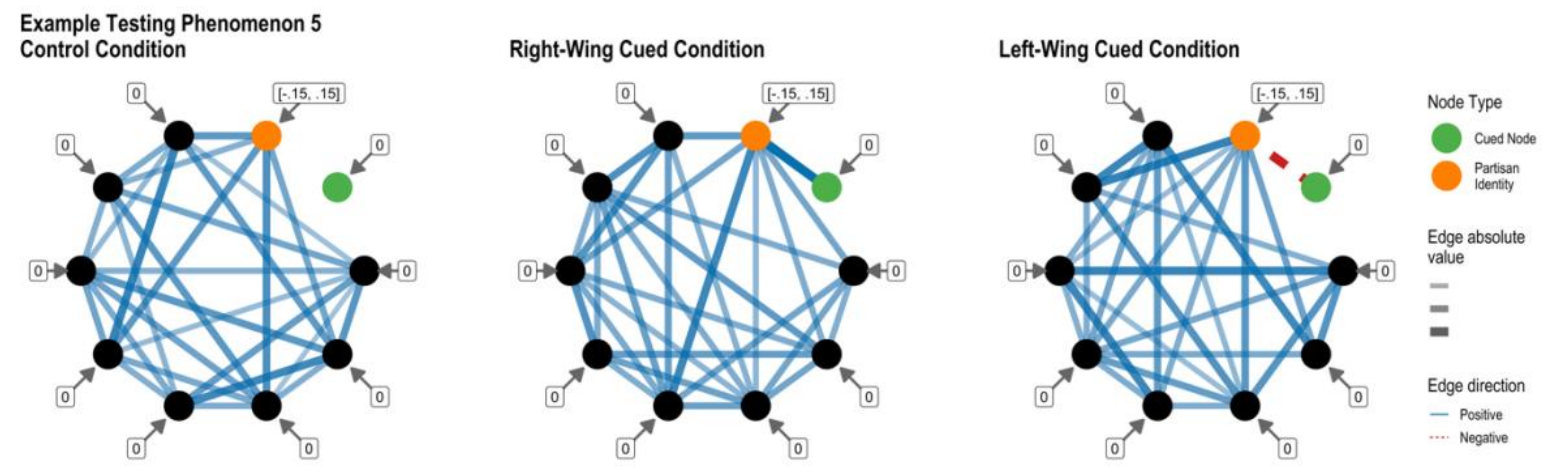

Figure 9. Example belief system networks for testing phenomenon 5. Edge (i.e. path) size and opacity represent the absolute value of the edge weight (i.e. strength). Edge color and line type represent the direction (i.e. positive vs. negative) of the edge's influence. For this example, all edges are positive for the first 50 time points. After the first 50 time points, edges are added that link the cued node to the partisan identity nodes. The added edge is positive in the right-wing cue condition (.15) and the edge is negative in the left-wing cue condition (-.15). Incoming arrows represent possible exogenous influence. For this example, exogenous influence is set at 0 for all nodes with the exception of the partisan identity node. For the partisan identity node, this ranged from -.2 to .2 in steps of .05 , excluding 0 . 
The results are shown in Figure 10. An in-party cue results in an attitude that aligns with the partisan identity, while in the control condition no attitude change occurs. The opposite pattern is found for out-party cues. Connecting the cued node to an out-party cue results in an attitude in the opposite direction of the partisan identity. These results replicate the findings of partisan cue experiments.

The literature on party cues have identified a number of potential moderators, including the need for cognition and party identity strength (Kam, 2005; Bakker et al., 2020). Because the empirical evidence for some of these moderators is mixed, we focused on the more often replicated effect of party cues (sans moderation). Nonetheless, scholars in the party cue domain may find it useful to consider how these different moderators can be incorporated into this network approach as a method for both identifying new moderators and understanding the conditions when established moderators may be more or less likely to emerge.

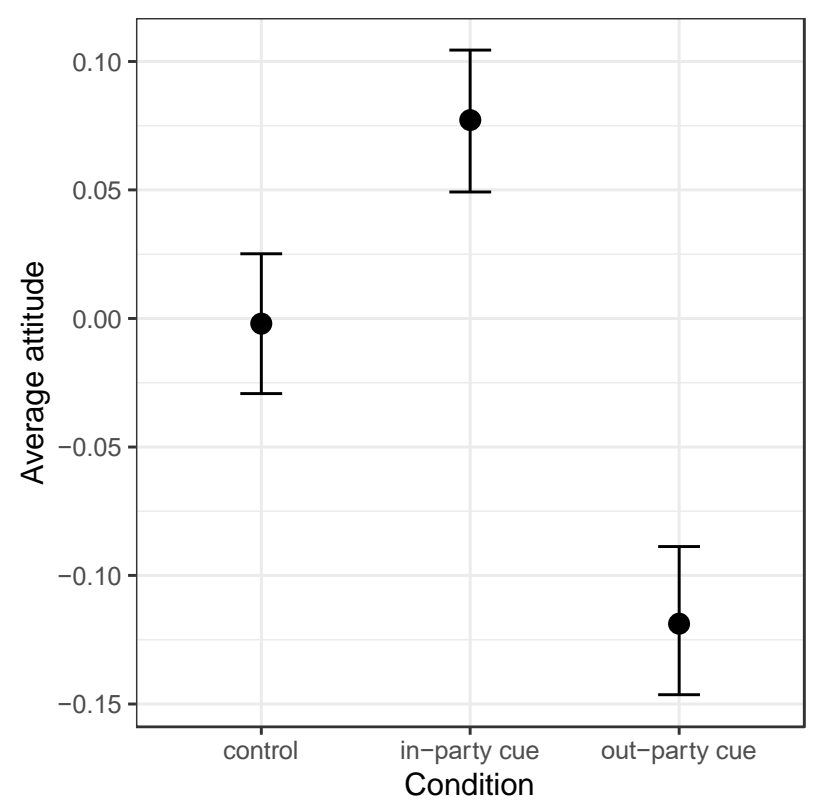

Figure 10. The average attitude across the three partisan cue conditions. In the control condition, the cued node was isolated from the belief network, resulting in no attitude change. In the inparty cue condition, the cued node was positively connected to a partisan identity, resulting in a 
positive attitude change. In the out-party condition, the cued node was negatively connected to a partisan identity, resulting in a negative attitude change. Error bars reflect $95 \%$ confidence intervals. Note that the $y$-axis could range from -1 to 1 .

\section{Phenomenon 6: Liberal Consensus > Conservative Consensus > Moderate Consensus}

The prior phenomena are all individual-level phenomena that are expected to and are often found to extend across political systems (e.g., Bakker et al., 2020; Brader et al., 2020; Brader et al., 2014). Our simulations suggest that individual level belief system dynamics can produce these individual-level phenomena. For the last phenomena we consider, we move to the societal-level of analysis to see if individual level belief system dynamics can cohere into patterns observed at the societal level within the United States.

A robust regularity in United States politics is that self-identified liberals have more consensus than conservatives and conservatives have more consensus than moderates (Ondish \& Stern, 2018; although we focus on Ondish \& Stern's analysis, for related findings see Feldman \& Johnston, 2014; Lupton, Myers, \& Thornton, 2017). This means that when a liberal person tends to support some policy issues and oppose others, other liberals are likely to support and oppose the same issues. For conservatives, this is less likely. For moderates, this is the least likely. This phenomenon has been identified using data from both the American National Election Study and the General Social Survey, both of which contain representative samples of U.S. Americans across multiple decades. The original explanation (Ondish \& Stern, 2018) suggests that this phenomena occurs because conservatives are more motivated than liberals to form consensus and cohesion (Stern, West, \& Schmitt, 2014). This leads conservatives to form consensus on issues among their immediate social circle and community (e.g., family, church group; Jost, Ledgerwood, \& Hardin, 2008), which decreases the amount of similarity at a broader, societal level (i.e. the level of analysis relevant for this phenomenon). Presumably, because moderates do 
not have a clear ideological affiliation, they show the least consensus. We show how this liberal consensus $>$ conservative consensus $>$ moderate consensus pattern can be accounted for with our model of individual belief system dynamics.

To demonstrate how the dynamics of belief systems operate in the United States and can account for the liberal consensus finding in the United States, we need to make some plausible assumptions about belief systems in the United States. First, we need to make plausible assumptions about the exogenous influences in our simulations. Political attitudes in the United States do not randomly vary around a neutral midpoint. Rather, extensive analysis of public opinion data has shown that Americans' attitudes on matters of policy (e.g., spending on social welfare programs, social security) leans to the left, whereas Americans' identification with ideological labels leans to the right (for a complete discussion and analysis see Ellis \& Stimson, 2012). Putting aside why this pattern emerges, this pattern means that when we set the exogenous influences for our simulations, we need to set the exogenous influences for the nodes representing policy attitudes to be somewhat to the left on average, whereas we need to set the exogenous influences for the nodes representing ideological identification to be somewhat to the right on average. Because policy attitudes and ideological identifications are often correlated, the exogenous influences for both policy attitudes and identifications for any given simulated participant should also be correlated.

Second, we need to make plausible assumptions about the similarity in the structure of the belief system. In our prior simulations, we have assumed that all of the participants have their own unique belief system. Our decision to use unique belief systems in the prior simulations was made so that we could demonstrate that the results of the simulations generalize across different belief system structures and are not due to idiosyncrasies in the structure of any one simulated 
belief system. However, there is likely to be some degree of consensus in how attitudes and identities are connected in a single political system due to shared experiences in the system (Goldberg \& Stein, 2018), elite influence (Converse, 1964), and normative expectations (Groenendyk, Kimbrough, \& Pickup, 2020). For example, Baldassarri and Goldberg (2014) found that policy issues were primarily (but not exclusively) positively correlated in American samples. At the same time, policy issues were more strongly correlated (e.g., constrained) for some parts of the population compared to others. Therefore, in our simulations, we use the same base belief system for each participant, but manipulate the constraint (using the same method as the simulation testing phenomenon 1 and 2). These two assumptions combined with our model of belief system dynamics is sufficient to account for the liberal consensus effect.

We simulated 40 different populations, representing different years following the design of Ondish and Stern (2018). Each population had it's own base network of all positive connections and a connection probability of .8 (see Figure 11). Each population consisted of 1000 participants with a belief system based on the base network (consistent with the second assumption above), but with more or less constraint by multiplying the edges of the base network with a connectivity multiplier consisting of either $0.5,1,2,3$, or 4 . 


\section{Example Testing Phenomenon 6}

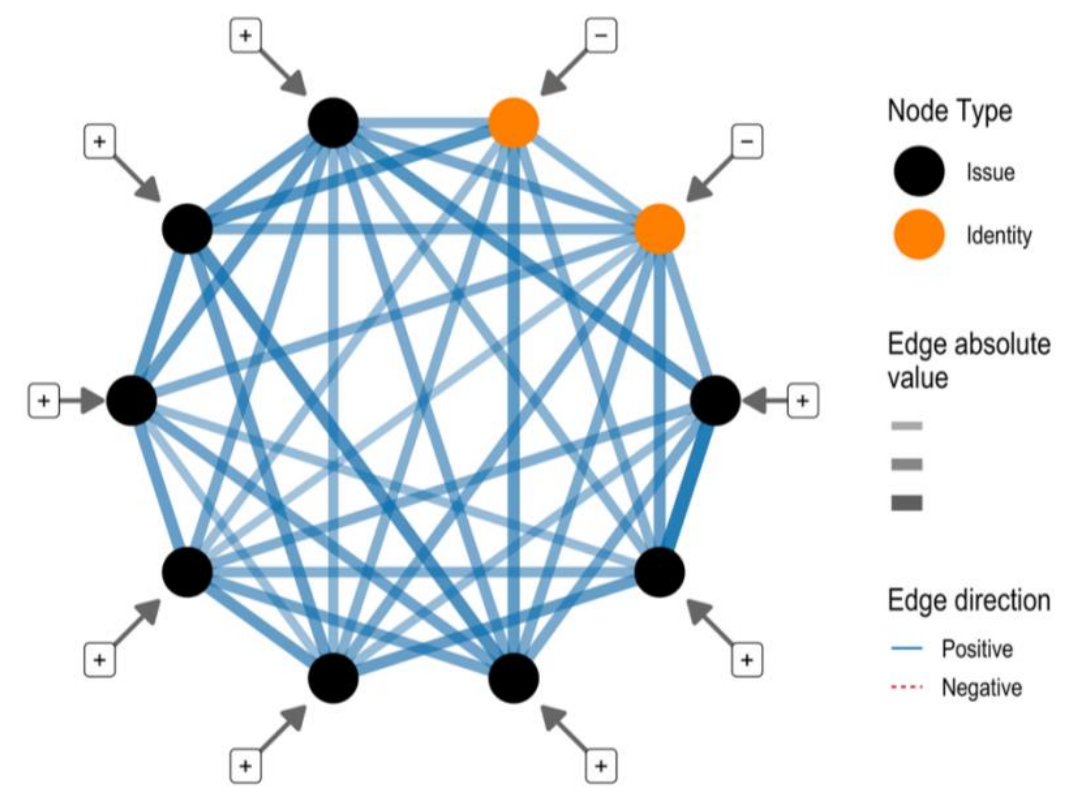

Figure 11. Example belief system networks for testing phenomena 6. Edge (i.e. path) size and opacity represent the absolute value of the edge weight (i.e. strength). All edges were positive, with a .8 connection probability. Two nodes were defined as partisan identity nodes, whose exogenous influences were generated by drawing values from a normal distribution with a slightly conservative/right-wing average $(M=0.02, S D=0.04$, based on symbolic ideology from Ellis \& Stimson, 2012). Eight nodes were defined as issue nodes, whose exogenous influences were generated by multiplying the base identity exogenous influences by .25 and summing it with a random value drawn from a normal distribution with a slightly left-wing average $(M=$ $0.03, S D=0.04)$. In order to prevent identical exogenous influences for each participant, some random noise $(M=0, S D=0.01)$ was added to each exogenous influence. The networks evolved for a period of 20 time points.

Each participant had their own exogenous influences. The exogenous influences were generated with three steps so that these influences would match the first assumption above about the distribution of attitudes in the United States. First, for each participant, their base exogenous influence for identity nodes was generated by drawing values from a normal distribution with a slightly conservative/right-wing average $(M=0.02, S D=0.04$, based on symbolic ideology from Ellis \& Stimson, 2012). Second, for each participant, their base exogenous influence for issue nodes was generated so that it would both be correlated with the exogenous influences for the 
identity nodes and be left-wing on average. This reflects both the tendency for identities and issues to correlate, as well as the tendency for Americans to adopt liberal/left-wing policies on average (Ellis \& Stimson, 2012). To do this, the base issue exogenous influence was created by multiplying the base identity exogenous influence by 0.25 and summing it with a random value drawn from a normal distribution with a slightly left-wing average $(M=0.03, S D=0.04)$. Third, so that each node did not have an identical exogenous influences for each participant random noise $(M=0, S D=0.01)$ was added to each base exogenous influence. Two nodes were considered identity nodes (e.g., roughly reflecting identification and liberal/conservative and leftwing/right-wing) and the remaining nodes were considered issue nodes. The networks then evolved for a period of 20 time points.

We followed the same analysis strategy as the original paper documenting this phenomenon (Ondish \& Stern, 2018). First, we grouped people as liberals, moderates, or conservatives by finding their average opinion on the two identity nodes across the 20 time points. People with opinions $<-0.5$ were categorized as liberal, people with opinions $>0.5$ were categorized as conservative, and the people in the middle were categorized as moderates. Then, we calculated each participants' average opinion for each of the 8 issue nodes across the 20 time points. Lastly, for the three political groupings, we calculated consensus on the eight issue node averages using a "one-to-many" variation of the Social Relations Model (Kenny, Kashy, \& Cook, 2006). This essentially consists of the ICC for issue when an intercept-only multilevel model is estimated with issues nested in individuals. It captures the degree people tend to agree or disagree on the same set of issues. The issues were each averaged across timepoints before the model was estimated. The liberal consensus phenomenon predicts that liberals will have higher issue ICCs (i.e. consensus) than conservatives who will have higher consensus than moderates. 
The results are displayed in Figure 12. Across 40 different populations, liberals had the highest consensus in $35(87.5 \%)$ populations while conservatives had the highest consensus in 5 (12.5\%). Moderates did not have the highest consensus in any of the 40 populations. Putting aside liberal participants, conservatives had more consensus than moderates in $34(87.5 \%)$ of the populations (in 1 population, both moderates and conservatives had 0 consensus). These results replicate the U.S. American liberal consensus phenomenon. Liberals showed more consensus than conservatives, who in turn showed more consensus than moderates in our simulation of U.S. American belief system dynamics.

The liberal consensus effect seems to occur because policies are pushed in a liberal/leftwing direction by the exogenous influences for all of the simulated participants. This leads a situation where policies tend to be more similar for liberals. For conservatives, the exogenous influences tend to push policies away from their preferences. The belief system structure (i.e. the edges of the network) are necessary because they ensure that the policy nodes move together and similarly for all participants. Notably, Ondish and Stern's (2018) theoretical explanation suggests that the liberal consensus effect will emerge across countries, whereas our explanation suggests that whether or not the liberal consensus effect emerges depends on the patterns of exogenous influences for symbolic (identity) and operational (policy) components of the belief system. 


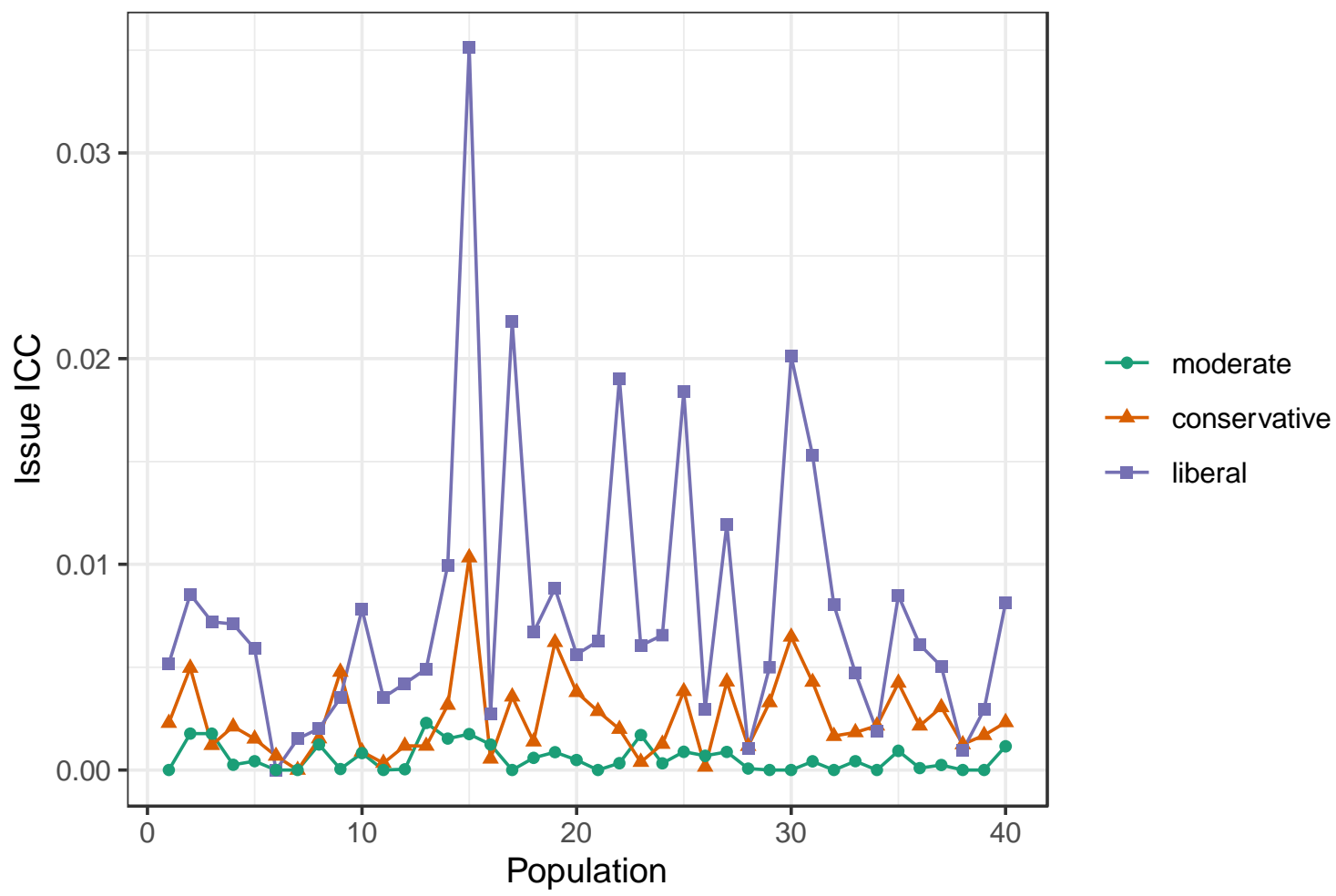

Figure 12. The intraclass correlations (ICC) of issues from 40 intercept-only multilevel models with issues nested in individuals, representing consensus.

\section{General Discussion}

Belief systems are a central construct in the social sciences with relevance to a diverse array of phenomena and subdisciplines. Our goal with this paper was to develop a theory of belief system dynamics. We propose that any theory of belief system dynamics needs to incorporate at least three features: (1) elements of the belief system need to be connected in some way for at least some people, (2) the connections between elements must be causal, and (3) the theory needs to allow for the possibility that belief systems are influenced by exogenous factors. One way to satisfy these necessary components is to build on prior work that has conceptualized belief systems as networks (Boutyline \& Vaisey, 2017; Brandt et al, 2019; Friedkin et al., 2016; Goldberg \& Stein, 2018) or complex systems (Homer-Dixon et al., 2013). We implement the theory of belief systems as networks using the dynamic Ising model in order to formally test 
model predictions. Our approach allowed us to go beyond past work that has estimated belief system networks without modeling their dynamics (e.g., Boutyline \& Vaisey, 2017; Brandt et al., 2019), discussed belief systems as networks without implementing such a theory (Home-Dixon et al., 2013), and modeled belief system dynamics but not attempted to integrate disparate phenomenon (Friedkin et al., 2016; Goldberg \& Stein, 2018). The dynamic Ising model implementation, with only a few assumptions, was able to integrate six different heretofore unrelated phenomena in the belief systems literature.

\section{What is "Hardcore" of Theory?}

A verbal theory or narrative review might be able to integrate the same phenomenon we discuss here. A notable feature of our approach, however, is that we not only proposed a verbal theory, we also showed how that theory can be implemented in both mathematical equations and simulations. And then we showed that this theory can integrate otherwise unrelated phenomena. Guest and Martin (2020) recently highlighted how psychologists often skip from a broad theoretical framework to a hypothesis without working out the specification of the theory or its implementation and simulation (see also Borsboom, van der Maas, Dalege, Kievit, \& Haig, 2020). These intermediary steps are useful because they make (sometimes) vague theoretical statements and the implications of those statements concrete. By making them concrete, future work can test hypotheses that have a tighter link between the hypothesis and the verbal theory. We aim to start to fill the specification and implementation gap for the belief systems literature by developing our belief systems as network theory and its implementation in the dynamic Ising model.

Guest and Martin (2020) also highlight that failures at any step in the scientific process require that we go back and adjust the prior step before continuing down the path. Just as when 
data fail to support our hypotheses we go back and adjust the hypothesis (and then test it again), when a hypothesis is not confirmed we should go back and adjust our implementation (and potentially specification and broader theory). This raises the question of what kinds of adjustments do we see as damaging to our theoretical hardcore (to borrow from Lakatos, 1978)?

Our theoretical hardcore is that a political belief system is a network of causally connected attitudes and identities which, via the interactions between the nodes and the push of exogenous influences, produces the disparate phenomena in the belief systems literature. We have implemented it, in this paper, in the dynamic Ising model. Others may implement the theoretical hardcore in other ways (e.g., as parallel constraint satisfaction networks, Goldberg \& Stein, 2018). Indeed, parallel constraint satisfaction models are based on Hopfield neural networks (Monroe \& Read, 2008) which are based on Ising models (Hopfield, 1982; see also Gurney, 1997; Thagard \& Verbeurgt, 1998). As discussed by Dalege and colleagues (Dalege, Borsboom, van Harreveld, \& van der Maas, 2018) in the context of work on individual attitudes, both simpler Ising models and more complex parallel constraint satisfaction models have tradeoffs. Whereas Ising models have fewer assumptions, parallel constraint satisfaction models are more flexible. We think it is notable that using the Ising model allowed us to account for several unrelated phenomenon. Yet, if another implementation accounts for the same (or more) phenomena as our implementation and makes accurate, new predictions with a similar number of assumptions, such an implementation would be more valuable than ours. Similarly, if the implications of our implementation are not borne out in the data, then it would suggest that changes in the implementation are necessary. At the same time, different implementations of the theoretical hardcore would still be consistent with our theoretical hardcore. If it is not possible to amend an implementation (our implementation or otherwise) that is consistent with the 
theoretical hardcore and with the data, then changes to that hardcore will be necessary. For example, if the attitudes and identities that make up a belief system do not influence one another (in the way we specified or otherwise) our theoretical hardcore would be falsified.

\section{What Aren't We Claiming?}

We claim that political belief systems are networks of causally connected attitudes and identities that can be implemented in a dynamic Ising model. Despite the usefulness of this model, it does not cover all of the possible questions related to belief systems. For example, although our model integrates a number of phenomena in the belief systems literature, we do not explain such common questions about why there are ideological differences in some psychological traits between liberals or conservatives (Bakker \& de Vreese, 2016; Gerber, Huber, Doherty, Dowling, \& Ha, 2010; Xu, Plaks, \& Peterson, 2016). Although differences in belief system network structure might help explain some differences between liberals and conservatives (see phenomenon 6), many questions about asymmetries between liberals and conservatives are for constructs exogenous to the belief system (Jost, 2017). In this way, this existing literature is a complement to our work by highlighting potential exogenous influences that are summarized in the $\alpha$ parameter of our model. Our model comes into contact with the prior work on ideological differences when researchers investigate how change in the $\alpha$ parameter affect the dynamics of the belief system.

We also do not make claims about the origins of belief system edges. That is, where do the connections between the attitudes and identities in the belief system come from? One promising answer is that people observe attitudes and identities co-occurring in their environment, leading them to become linked in the network. Such observations may come from direct interactions with and observations of families, peers, and others in the society (for related, 
but different simulated models of this process see Baumann, Lorezn-Spreen, Sokolov, \& Starnini, 2020; Goldberg \& Stein, 2018; Schweighofer, Schweitzer, \& Garcia, 2020). Other observations are likely to come from elites, such as in our simulation of party cues phenomenon in the section above (for further discussion see Bakker et al., 2020; Bullock, 2011; Cohen, 2003).

A related belief system network approach to our own (Boutyline \& Vaisey, 2017) proposes a model of belief system development. The idea is that a belief system begins development with a single ancestor attitude and this ancestor attitude causes people's positions on new attitudes in a second generation. These new attitudes may then, in turn, cause people's positions on additional new attitudes in a third generation. And this process would repeat across many generations of attitudes until the entire belief system is formed. This creates a belief system that is a tree graph, or a directed acyclic graph. Although this model may describe the process for forming the belief system, it's causal structure is unidirectional (ancestor attitude $\rightarrow$

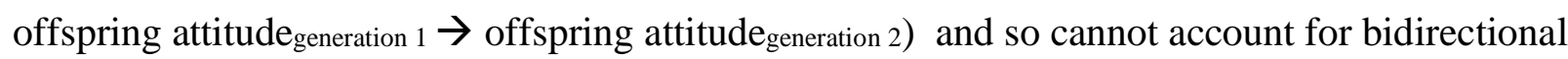
relationships between belief system elements, nor interactions between attitudes and identities that are in different branches of the belief system. Our model can. To the extent the Boutyline and Vaisey's (2017) model of belief system development captures the developmental process, our model may then serve as a guide for belief systems that have already been developed.

The belief systems as networks approach assumes that the attitudes and identities in the network causally influence each other. We model this as it occurs over time; however, the unit of time in our simulations is arbitrary (e.g., 1 unit of time could be anything from 1 millisecond to 15 minutes to 1 year). The timescale of causality between attitudes and identities is not known. For example, although longitudinal studies across years show that many political attitudes are relatively stable (e.g., Kiley \& Vaisey, 2020; Osborne \& Sibley, 2020), if the causal interactions 
take place on a faster timescale (e.g., seconds) such studies (and no known studies) would detect such connections. Similarly, if belief system dynamics are primarily present during certain developmental stages (e.g., early adulthood, Kiley \& Vaisey, 2020; Rekker, Keijsers, Branje, \& Meeus, 2015, 2017), empirical studies could quite easily overlook relevant dynamics. ${ }^{12}$ A related possibility is that the belief system dynamics we have simulated do not engage unless a person is thinking about politics. In this way, a belief system functions as a type of mental representation that is used when it is brought to mind by either situational factors (e.g., seeing a racist bumper sticker, reading the news, protesting police brutality) or chronic activation of politics (e.g., people with high interest and engagement in politics). These details of the model are not yet known.

Our model was influenced by prior empirical work that treated belief systems as networks (Baldassarri \& Goldberg, 2014; Boutyline \& Vaisey, 2017; Brandt, Sibley, \& Osborne, 2019; Fishman \& Davis, in press). A fundamental difference between our theoretical work here and the prior empirical work is the level of analysis. Therefore, we are not claiming that the model we propose here necessarily justifies nor confirms prior empirical work on belief system networks. The belief system network in our implementation here is at the level of the individual, reflecting our assumption that belief systems, as a psychological construct, exist at the level of the person (see also Homer-Dixon et al., 2013; Morgan \& Wisneski, 2017). Each individual is assumed to have their own belief system where the nodes causally affect the nodes within each individual. Notably, although we believe that belief systems are at the individual level, this does not mean that structure of belief systems are not shared. For example, although we modeled

\footnotetext{
${ }^{12} \mathrm{We}$ anticipate that the belief system dynamics we've simulated are primarily present across developmental stages in adults because the phenomena we simulated are readily identified in the general population.
} 
belief systems at the individual level for phenomenon 6 , we also assumed that each simulated participant shared a similar belief system structure.

The focus on the individual level of analysis is in contrast with empirical work on belief system networks. The empirical work estimates belief system networks using techniques best equipped for between-subjects comparisons (e.g., cross-sectional correlations or partial correlations). The networks that are estimated therefore are statistical representations of the political cleavages in society more so than the belief systems in "someone's head" (Martin, 2000). Although observing such cleavages seem likely to affect individuals' belief system structure (Goldberg \& Stein, 2018), it makes such between-subject belief systems potentially uninformative for assessing the propositions of our model or providing estimates of $\alpha$ and $\beta$ in our model (see Marsman, 2019 and Marsman, Waldorp, \& Borsboom, 2019 for one possible way to think about the relationship between within-person psychological networks and betweenperson psychological networks). For example, it may be the case that between-subject belief system networks are an average belief system across participants, where each participants individual belief system is a deviation from that average; however, even in such an ideal situation it is likely that some edges will be negative for some subset of the population (cf. Baldassarri \& Goldberg, 2014). Such negative edges are likely to have significant impact on the dynamics of those belief systems (see phenomenon 3).

\section{What Are Plausible Uses and Extensions?}

Our simulations demonstrated that the belief systems as networks approach can integrate and explain at least six phenomena. This is our primary contribution. There are several next steps that can be taken. 
First, as noted above, existing methods for estimating belief system networks do not estimate the necessary parameters for individual-level belief systems. By developing the theory and showing the utility of the network approach at the individual level, we show the necessity of developing new methods for estimating individual level belief system networks. Although there are no clear front runners, existing methods to assess conceptual associations (e.g., Stolier, Hehman, \& Freeman, 2020), perceived causal associations (Frewen, Allen, Lanius, \& Neufeld, 2012), and representations (e.g., Thagard, 2010) may provide a jumping off point for developing the necessary methods.

Second, until such measures are adequately developed, researchers can use simulations to test their hypotheses and to see what the theory would predict under different circumstances. Then they can conduct the necessary empirical study to see if the empirical and simulation results are consistent. For example, researchers interested in party cues may use simulations to test hypotheses about moderators of party cue effects (cf. Bakker et al., 2020; Kam, 2005) or use the structure of the belief system to predict what attitudes are more or less likely to show party cue effects (cf. Guisinger \& Saunder, 2017; Tappin, 2020). Such researchers could simulate their research situation as belief system networks, observe the results of the simulations, conduct a new experiment, and assess if patterns of results are similar.

Third, just as new simulations can reveal patterns that should be confirmed in empirical data, our simulations of the six phenomena highlighted several possible new phenomena that require testing. For example, across the two of the phenomenon we tested we found that midlevels of connectivity produced some patterns that were unexpected when considering prior data. When testing how constraint can produce stability we found (as do other implementations of the Ising model) that mid-levels of connectivity results in more instability than low levels of 
connectivity. When testing for spillover effects, we found that spillover effects were most likely among people with mid-levels of connectivity. These two findings might not have been previously observed because the field did not have the measures of belief system connectivity with enough sensitivity to reliably detect mid-level connectivity, there are only a few people with mid-levels of connectivity making the phenomena rare in practice, or because our implementation and theory is wrong. This requires further testing.

Fourth, our simulations did not tackle every possible question in the belief systems literature. We think that one use of our model is to more fully explore a number of different phenomena. To facilitate this, we have shared all of our code publicly. This will make it easier for other researchers to adapt and build on our implementation to answer additional research questions. Here are seven.

1. What attitudes are we mostly likely to observe spillover effects (as in Phenomenon 4)? Our simulations suggest that spillover effects should only be expected in certain situations (e.g., following especially impactful manipulations or experiences). Other factors, such as network structure and the links between the targeted node(s) and the spillover node(s) is likely relevant and can be explored. For example, potential spillover nodes that are more strongly embedded in the network structure may show weaker spillover effects than potential spillover nodes that are more peripheral and disconnected from the rest of the network.

2. In the spillover simulations we demonstrated that direct effects of a manipulation on an attitude do not necessarily spill-over to connected attitudes in the belief system. Social psychologists have also flipped this notion on its head by considering how making connected attitudes (and values in some cases) salient or making the connections between 
related attitudes salient reduces the impact of the direct effects of the manipulation (Blankenship, Wegener, \& Murray, 2015; McGuire, 1981). Our model may be used to shed light onto when and why these effects are likely to happen.

3. What attitudes are likely to be easier or harder to change based on their location in the belief system network? Integrating work on belief system networks with work on network structure (e.g., centrality, density) and network control theory (Henry, Robinaugh, \& Fried, 2020), which aims to understand how dynamic systems can be modified, changed, and controlled, might be one starting point to answer this question.

4. How are belief systems likely to change (or not) when exposed to external pressures (e.g., experience of threat)? For example, if an economic collapse leads people to hold more left-wing policy positions, how might we expect that to impact the rest of their belief system? Are some belief system structures more or less susceptible to these exogenous influences?

5. How do belief system dynamics differ for groups with different belief system structures? For example, research hints at the possibility that political elites have belief systems with more constraint than people in the general public (e.g., Converge, 1964; Lupton et al., 2015). ${ }^{13}$ Our first two phenomena and simulations built on this approach can illuminate this. More interestingly, our approach can be used to illuminate belief system dynamics in groups who cluster attitudes in different ways. For example, recent work shows that Black Americans see human-oriented issues (e.g., unemployment, lack of access to grocery stores) as environmental issues more so than White Americans (Song et al.,

\footnotetext{
${ }^{13}$ We say that research only "hints" this because these studies typically use between-subject comparisons which may or may not map onto within-subject belief system structure as simulated in our work. The higher levels of constraint observed in elites in between-subject comparisons might be due to great sorting among elites compared to the general population rather than a stronger link between belief system elements in the individual.
} 
2020). This difference may play out in different belief system dynamics in these groups, especially the interplay between nodes representing environmental and human-oriented issues.

6. Just as group might differ in the structure of their belief systems (see \#4), they may also differ in the extent of exogenous influence. We saw this in our simulations of crosspressures, but such simulations could also be adapted to understand how, for example, emotions differentially impact political attitudes and identities for different groups (e.g., Pheonix, 2019).

7. Our model was designed for political belief systems, but it may be applied to other belief systems (e.g., religious belief systems). It is an open question as to whether there will be similar dynamics in different domains.

Regardless of the specific question, our approach is flexible enough to accommodate a range of research questions and our code is available which takes some of the guesswork out of such an implementation.

Just as there are plausible uses of our implementation in its current form, there are also plausible extensions that might help scholars address other research questions. Some extensions are modifications of some of our (simplifying) assumptions. For example, we assumed that all of the edges in the belief system networks are bidirectional, with the elements of the belief systems causally and reciprocally affecting each other. However, in some cases there may be good reason to abandon this simplifying assumption and to instead assume that causal influence for some elements (e.g., partisan identification) is primarily in one direction. The consequences for changing this assumption could be modeled for different phenomena. Similarly, we made the simplifying assumption that a node does not affect itself, however, it is possible that (some) 
nodes are self-perpetuating and influences themselves overtime. The consequences of selfperpetuating nodes for belief system dynamics is a plausible extension of our work. We also assumed that political identities were nodes in the belief systems; however, other simulations may explore the consequences of treating identities as a higher level features of the network (e.g., that constraints certain connections). As part of our simulations, we did not make any assumptions about the strength of the nodes; however, we know that people hold onto some attitudes with more strength than others (e.g., Pomerantz, Chaiken, \& Tordesillas, 1995). Building attitude strength into the model by specifying strong exogenous influence on a node that help the node resist change or specifying strong connections with a node's neighbors that help it resist change may be possible.

It will also be useful to connect work on social networks, belief system networks, and the networks underlying individual attitudes. We suggest that political belief systems are networks of political attitudes and identities. This seemingly simple proposition suggests that the dynamics of individual attitudes and identities cannot be fully understood without understanding how those attitudes and identities are situated among other related attitudes and identities. This possibility is overlooked in both models of attitudes and models of the social processes that affect attitudes. For example, people's social networks influence both the stances people take on individual attitudes (McPherson, Smith-Lovin, \& Cook, 2001) and the strength at which they hold their attitudes (Visser \& Mirabile, 2004), but this work does not consider how those individual attitudes may also be embedded in a belief system with other attitudes. Similarly, computational models of individual attitudes, such as the Attitudes as Constraint Satisfaction model (Monroe \& Reed, 2008) and the Causal Attitude Network model (Dalege et al., 2016, 2018), share the assumption that individual attitudes consist of networks of affective and cognitive responses to 
the attitude object that dynamically shape one another to produce the phenomenology of an individual attitude, but these models do not consider how the resulting attitudes may also shape and be shaped by additional attitudes in a belief system. Similarly, our approach does not attempt to integrate belief system networks with social networks nor attitude networks. Such integration will provide a more comprehensive map of how attitudes and belief systems are embedded in our social systems and in one another.

Lastly, we simulated belief system networks based on a random network model (Erdos \& Renyi, 1959) with nodes all taking on left-wing or right-wing values. However, other belief system structures are possible. One particularly interesting direction would be to simulate belief systems with different clusters. This could approximate the cultural and economic clusters found in factor analyses of political attitudes (Feldman \& Johnston, 2014; Johnston \& Ollerenshaw, 2020) or corresponding to separate but overlapping belief systems (e.g., political and religious belief systems; Friesen \& Ksiazkiewicz, 2015; McKenzie \& Rouse, 2013). In such cases, the nodes would still take on left-wing or right-wing values, but would be in different clusters depending on whether they are nodes representing economic or cultural issues. In this way, although our model takes a primarily unidimensional approach (cf. Azevedo et al., 2019), it can be extended to include additional clusters of nodes in order to simulate increasingly complex belief systems. Such approaches might be necessary to incorporate ideologies that have belief systems including a mix of left-wing social policies and right-wing economic policies (e.g., Libertarians).

\section{Conclusions}

We've implemented a theory of belief systems in the dynamic Ising model. Our theory and implementation integrates six phenomena in the belief systems literature, including findings 
related to attitude consistency, cross-pressures, spillover effects, party cues, and attitude consensus. This phenomena range from descriptive, cross-sectional phenomena (e.g., attitude consistency, cross-pressures), to experimental (e.g., spillover effects, party cues) and societallevel phenomenon (e.g., attitude consensus). The range of phenomena highlight how our model of belief systems as emerging from the interactions between individual belief system elements can integrate phenomena at different levels of analysis in the belief system literature. Our model is not the end, but rather is just one step in building a formal model of belief systems to help integrate research and make new predictions. 


\section{References}

Albarracin, D., \& Vargas, P. (2010). Attitudes and persuasion: From biology to social responses to persuasive intent. In S. T. Fiske, D. T. Gilberg, \& G. Lindzey (Eds.), Handbook of Social Psychology (pp.394-427). John Wiley \& Sons.

Azevedo, F., Jost, J. T., Rothmund, T., \& Sterling, J. (2019). Neoliberal ideology and the justification of inequality in capitalist societies: Why social and economic dimensions of ideology are intertwined. Journal of Social Issues, 75, 49-88.

Bakker, B. N., \& de Vreese, C. H. (2016). Personality and European Union attitudes: relationships across European Union attitude dimensions. European Union Politics, 17, 25 45.

Bakker, B. N., Lelkes, Y., \& Malka, A. (2020). Understanding partisan cue receptivity: Tests of predictions from the bounded rationality and expressive utility perspectives. Journal of Politics, 82, 1061-1077.

Baldassarri, D., \& Goldberg, A. (2014). Neither ideologues nor agnostics: Alternative voters’ belief system in an age of partisan politics. American Journal of Sociology, 120, 45-95.

Banaji, M. R., \& Heiphetz, L. (2010). Attitudes. In S. T. Fiske, D. T. Gilberg, \& G. Lindzey (Eds.), Handbook of social psychology (pp.353-393). John Wiley \& Sons.

Baumann, F., Lorenz-Spreen, P., Sokolov, I. M., \& Starnini, M. (2020). Emergence of polarized ideological opinions in multidimensional topic spaces. arXiv.

\section{https://arxiv.org/abs/2007.00601}

Blankenship, K. L., Wegener, D. T., \& Murray, R. A. (2015). Values, inter-attitudinal structure, and attitude change: Value accessibility can increase a related attitude's resistance to change. Personality and Social Psychology Bulletin, 41, 1739-1750. 
Boonen, J., Pedersen, E. F., \& Hooghe, M. (2017). The effect of political sophistication and party identification on voter-party congruence. A comparative analysis of 30 countries. Journal of Elections, Public Opinion and Parties, 27, 311-329.

Borsboom, D., van der Maas, H., Dalege, J., Kievit, R., \& Haig, B. (2020, February 29). Theory Construction Methodology: A practical framework for theory formation in psychology. https://doi.org/10.31234/osf.io/w5tp8

Boutyline, A., \& Vaisey, S. (2017). Belief network analysis: A relational approach to understanding the structure of attitudes. American Journal of Sociology, 122, 1371-1447.

Bullock, J. G. (2011). Elite influence on public opinion in an informed electorate. American Political Science Review, 105, 496-515.

Brader, T., De Sio, L., Paparo, A., \& Tucker, J. A. (2020). "Where You Lead, I Will Follow”: Partisan Cueing on High-Salience Issues in a Turbulent Multiparty System. Political Psychology, 41, 795-812.

Brader, T., Tucker, J. A., \& Therriault, A. (2014). Cross pressure scores: An individual-level measure of cumulative partisan pressures arising from social group memberships. Political Behavior, 36(1), 23-51.

Brandt, M. J. (2017). Predicting ideological prejudice. Psychological Science, 28, 713-722.

Brandt, M. J., Sibley, C. G., \& Osborne, D. (2019). What is central to political belief system networks?. Personality and Social Psychology Bulletin, 45, 1352-1364.

Brandt, M., Turner-Zwinkels, F. M., Karapirinler, B., van Leeuwen, F., Bender, M., van Osch, Y., \& Adams, B. G. (in press). The association between threat and politics depends on the type of threat, the political domain, and the country. Personality and Social Psychology Bulletin. 
Broockman, D., \& Kalla, J. (2016). Durably reducing transphobia: A field experiment on doorto-door canvassing. Science, 352, 220-224.

Brown-Iannuzzi, J. L., Lundberg, K. B., \& McKee, S. (2017). The politics of socioeconomic status: how socioeconomic status may influence political attitudes and engagement. Current Opinion in Psychology, 18, 11-14.

Campbell, A., Converse, P. E., Miller, W. E., \& Stokes, D. E. (1960). The American voter. New York: Wiley.

Choma, B., Hodson, G., Jagayat, A., \& Hoffarth, M. R. (2020). Right-wing ideology as a predictor of collective action: a test across four political issue domains. Political Psychology, 41, 303-322.

Cohen, G. L. (2003). Party over policy: The dominating impact of group influence on political beliefs. Journal of Personality and Social Psychology, 85, 808-822.

Converse, P. E. (1964). The nature of belief systems in mass publics. In D. E. Apter (Ed.), Ideology and discontent (pp. 206-261). New York, NY: The Free Press.

Conway III, L. G., Chan, L., \& Woodard, S. R. (2020). Socio-ecological influences on political ideology. Current Opinion in Psychology, 32, 76-80.

Coppock, A. \& Green, D. P. (in press). Do belief systems exhibit dynamic constraint? Journal of Politics

Cramer, A. O., van Borkulo, C. D., Giltay, E. J., van der Maas, H. L., Kendler, K. S., Scheffer, M., \& Borsboom, D. (2016). Major depression as a complex dynamic system. PloS one, 11, e0167490.

Cruz, S. M. (2017). The relationships of political ideology and party affiliation with environmental concern: A meta-analysis. Journal of Environmental Psychology, 53, 81-91. 
Csardi G. \& Nepusz, T. (2006). The igraph software package for complex network research. InterJournal, 1695.

Dalege, J., Borsboom, D., van Harreveld, F., van den Berg, H., Conner, M., \& van der Maas, H. L. (2016). Toward a formalized account of attitudes: The causal attitude network (CAN) model. Psychological Review, 123, 2-22.

Dalege, J., Borsboom, D., van Harreveld, F., \& van der Maas, H. L. (2017). Network analysis on attitudes: A brief tutorial. Social Psychological and Personality Science, 8, 528-537.

Dalege, J., Borsboom, D., van Harreveld, F., \& van der Maas, H. L. (2018). The Attitudinal Entropy (AE) Framework as a general theory of individual attitudes. Psychological Inquiry, 29, 175-193.

Dawes, C. T., \& Weinschenk, A. C. (2020). On the genetic basis of political orientation. Current Opinion in Behavioral Sciences, 34, 173-178.

DellaPosta, D. (2020). Pluralistic collapse: The "oil spill" model of mass opinion polarization. American Sociological Review, 85, 507-536.

Eadeh, F. R., \& Chang, K. K. (2020). Can threat increase support for liberalism? New insights into the relationship between threat and political attitudes. Social Psychological and Personality Science, 11, 88-96.

Eagly, A. H., \& Chaiken, S. (1993). The psychology of attitudes. Harcourt Brace Jovanovich College Publishers.

Ellis, C., \& Stimson, J. A. (2012). Ideology in America. Cambridge University Press.

Epskamp, S., Borsboom, D., \& Fried, E. I. (2018). Estimating psychological networks and their accuracy: A tutorial paper. Behavior Research Methods, 50, 195-212.

Erdos, P. \& Renyi, A. (1959). On random graphs. Publicationes Mathematicae, 6, 290-297. 
Farris, E. M., \& Holman, M. R. (2017). All politics is local? County sheriffs and localized policies of immigration enforcement. Political Research Quarterly, 70, 142-154.

Feldman, S., \& Johnston, C. (2014). Understanding the determinants of political ideology: Implications of structural complexity. Political Psychology, 35, 337-358.

Festinger, L. (1957). A theory of cognitive dissonance. Stanford, CA: Stanford University Press.

Fishman, N., \& Davis, N. T. (in press). Change we can believe in: Structural and content dynamics within belief networks. American Journal of Political Science.

Fleury, C. J., \& Lewis-Beck, M. S. (1993). Anchoring the French voter: Ideology versus party. Journal of Politics, 55, 1100-1109.

Frewen, P. A., Allen, S. L., Lanius, R. A., \& Neufeld, R. W. (2012). Perceived causal relations: novel methodology for assessing client attributions about causal associations between variables including symptoms and functional impairment. Assessment, 19, 480-493.

Friedkin, N. E., Proskurnikov, A. V., Tempo, R., \& Parsegov, S. E. (2016). Network science on belief system dynamics under logic constraints. Science, 354, 321-326.

Friesen, A., \& Ksiazkiewicz, A. (2015). Do political attitudes and religiosity share a genetic path?. Political Behavior, 37, 791-818.

Gawronski, B., Brochu, P. M., Sritharan, R., \& Strack, F. (2012). Cognitive consistency in prejudice-related belief systems: Integrating old-fashioned, modern, aversive, and implicit forms of prejudice. In B. Gawronski \& F. Strack (Eds.), Cognitive consistency: A fundamental principle in social cognition (pp. 369-389). New York, NY, US: Guilford Press. 
Gerber, A. S., Huber, G. A., Doherty, D., Dowling, C. M., \& Ha, S. E. (2010). Personality and political attitudes: Relationships across issue domains and political contexts. American Political Science Review, 104, 111-133.

Gerring, J. (1997). Ideology: A definitional analysis. Political Research Quarterly, 50, 957-994.

Glauber, R. J. (1963). Time-dependent statistics of the Ising model. Journal of Mathematical Physics, 4, 294-307.

Goldberg, A., \& Stein, S. K. (2018). Beyond social contagion: Associative diffusion and the emergence of cultural variation. American Sociological Review, 83, 897-932.

Groenendyk, E. W., Kimbrough, E. O., \& Pickup, M. (2020). How norms shape the nature and origins of mass belief systems. Retrieved from http://dx.doi.org/10.2139/ssrn.3541289

Guest, O. \& Martin, A. E. (2020). How computational modeling can force theory building in psychological science. PsyArXiv. 10.31234/osf.io/rybh9.

Guisinger, A., \& Saunders, E. N. (2017). Mapping the boundaries of elite cues: How elites shape mass opinion across international issues. International Studies Quarterly, 61, 425-441.

Gurney, K. (1997). An introduction to neural networks. CRC press.

Haas, I. J., Jones, C. R., \& Fazio, R. H. (2019). Social Identity and the Use of Ideological Categorization in Political Evaluation. Journal of Social and Political Psychology, 7, 335353.

Haslbeck, J. M., Epskamp, S., Marsman, M., \& Waldorp, L. J. (in press). Interpreting the Ising model: The input matters. Multivariate Behavioral Research.

Hatemi, P. K., \& McDermott, R. (2012). The genetics of politics: Discovery, challenges, and progress. Trends in Genetics, 28, 525-533. 
Heine, S. J., Proulx, T., \& Vohs, K. D. (2006). The meaning maintenance model: On the coherence of social motivations. Personality and Social Psychology Review, 10, 88-110.

Henry, T. R., Robinaugh, D., \& Fried, E. I. (2020, April 1). On the control of psychological networks. https://doi.org/10.31234/osf.io/7vpz2

Hillygus, D. S., \& Shields, T. G. (2008). The persuadable voter: Wedge issues in presidential campaigns. Princeton, NJ: Princeton University Press.

Homer-Dixon, T., Maynard, J. L., Mildenberger, M., Milkoreit, M., Mock, S. J., Quilley, S., ... \& Thagard, P. (2013). A complex systems approach to the study of ideology: Cognitiveaffective structures and the dynamics of belief systems. Journal of Social and Political Psychology, 1, 337-363.

Hopfield, J. J. (1982). Neural networks and physical systems with emergent collective computational abilities. Proceedings of the National Academy of Sciences, 79, 2554-2558.

Hopkins, D. J., \& Mummolo, J. (2017). Assessing the breadth of framing effects. Quarterly Journal of Political Science, 12, 37-57.

Huddy, L., Mason, L., \& Aarøe, L. (2015). Expressive partisanship: Campaign involvement, political emotion, and partisan identity. American Political Science Review, 109, 1-17.

Ising, E. (1925). Beitrag zur Theorie des Ferromagnetismus [Contribution to the theory of ferromagnetism.]. Zeitschrift fur Physik, 31, 253-258.

Johnston, C. D., \& Ollerenshaw, T. (2020). How different are cultural and economic ideology?. Current Opinion in Behavioral Sciences, 34, 94-101.

Jost, J. T. (2006). The end of the end of ideology. American Psychologist, 61, 651-670.

Jost, J. T. (2017). Ideological asymmetries and the essence of political psychology. Political Psychology, 38, 167-208. 
Jost, J. T., Ledgerwood, A., \& Hardin, C. D. (2008). Shared reality, system justification, and the relational basis of ideological beliefs. Social and Personality Psychology Compass, 2, 171186.

Jost, J. T., Federico, C. M., \& Napier, J. L. (2009). Political ideology: Its structure, functions, and elective affinities. Annual Review of Psychology, 60, 307-337.

Jost, J. T., Krochik, M., Gaucher, D., \& Hennes, E. P. (2009). Can a psychological theory of ideological differences explain contextual variability in the contents of political attitudes? Psychological Inquiry, 20, 183-188.

Jost, J. T., Stern, C., Rule, N. O., \& Sterling, J. (2017). The politics of fear: Is there an ideological asymmetry in existential motivation? Social Cognition, 35, 324-353.

Judd, C. M., \& Downing, J. W. (1990). Political expertise and the development of attitude consistency. Social Cognition, 8, 104-124.

Kalmoe, N. P. (2020). Uses and abuses of ideology in political psychology. Political Psychology, 41, 771-793.

Kam, C. D. (2005). Who toes the party line? Cues, values, and individual differences. Political Behavior, 27, 163-182.

Keating, D. M., \& Bergan, D. E. (2017). Mapping Political Attitudes: The Impact of Concept Mapping on Ideological Constraint. Communication Studies, 68, 439-454.

Kenny, D. A., Kashy, D. A., \& Cook, W. L. (2006). Dyadic data analysis. New York, NY: Guilford Press.

Kiley, K., \& Vaisey, S. (2020). Measuring Stability and Change in Personal Culture Using Panel Data. American Sociological Review, 85, 477-506. 
Kinder, D. R., \& Kalmoe, N. P. (2017). Neither liberal nor conservative: Ideological innocence in the American public. University of Chicago Press.

Kindermann, R., \& Snell, J. L. (1980). Markov random fields and their applications. Providence, RI: American Mathematics Society.

Kleppestø, T. H., Czajkowski, N. O., Vassend, O., Røysamb, E., Eftedal, N. H., SheehySkeffington, J., ... \& Thomsen, L. (2019). Correlations between social dominance orientation and political attitudes reflect common genetic underpinnings. Proceedings of the National Academy of Sciences, 116, 17741-17746.

Lakatos, I. (1978). The methodology of scientific research programmes. Cambridge University Press.

Latané, B. (1996). Dynamic social impact: The creation of culture by communication. Journal of Communication, 46, 13-25.

Lavine, H., Thomsen, C. J., \& Gonzales, M. H. (1997). The development of interattitudinal consistency: The shared-consequences model. Journal of Personality and Social Psychology, 72, 735-749.

Layman, G. C., \& Carsey, T. M. (2002). Party polarization and" conflict extension" in the American electorate. American Journal of Political Science, 46, 786-802.

Layman, G. C., Carsey, T. M., Green, J. C., Herrera, R., \& Cooperman, R. (2010). Activists and conflict extension in American party politics. American Political Science Review, 104, 324-346.

Lupton, R. N., Myers, W. M., \& Thornton, J. R. (2015). Political sophistication and the dimensionality of elite and mass attitudes, 1980- 2004. The Journal of Politics, 77, 368380. 
Lupton, R. N., Myers, W. M., \& Thornton, J. R. (2017). Party animals: asymmetric ideological constraint among Democratic and Republican Party activists. Political Research Quarterly, 70, 889-904.

Malka, A., \& Lelkes, Y. (2010). More than ideology: Conservative-liberal identity and receptivity to political cues. Social Justice Research, 23, 156-188.

Marsman, M. (2019). The idiographic Ising model. PsyArXiv, https://doi.org/10.31234/osf.io/h3ka5

Marsman, M., Waldorp, L., \& Borsboom, D. (2019). Towards a grand unified theory of network models, PsyArXiv, https://doi.org/10.31234/osf.io/n98qt

Martin, J. L. (2000). The relation of aggregate statistics on beliefs to culture and cognition. Poetics, 28, 5-20.

Martin, J. L. (2002). Power, authority, and the constraint of belief systems. American Journal of Sociology, 107, 861-904.

Mason, L. (2018). Losing common ground: Social sorting and polarization. The Forum, 16, 4766.

McGuire, W J. (1968). Personality and attitude change: An information-processing theory. In A. G. Greenwald, T. C. Brock, \& T. M. Ostrom (Eds.), Psychological foundations of attitudes (pp. 171-196). San Diego, CA: Academic Press.

McGuire, W. J. (1981). The probabilogical model of cognitive structure and attitude change. In R. E. Petty, T. M. Ostrom, \& T. C. Brock (Eds.), Cognitive responses in persuasion (pp. 291-308). Lawrence Erlbaum Associates, Inc.

McGuire, W. J. (1986). The vicissitudes of attitudes and similar representational constructs in twentieth century psychology. European Journal of Social Psychology, 16, 89-130. 
McKenzie, B. D., \& Rouse, S. M. (2013). Shades of faith: Religious foundations of political attitudes among African Americans, Latinos, and Whites. American Journal of Political Science, 57, 218-235.

McPherson, M., Smith-Lovin, L., \& Cook, J. M. (2001). Birds of a feather: Homophily in social networks. Annual Review of Sociology, 27, 415-444.

Monroe, B. M., \& Read, S. J. (2008). A general connectionist model of attitude structure and change: The ACS (Attitudes as Constraint Satisfaction) model. Psychological review, 115, 733.

Morgan, G. S., \& Wisneski, D. C. (2017). The structure of political ideology varies between and within people: Implications for theories about ideology's causes. Social Cognition, 35, 395414.

Nam, H. H., Jost, J. T., Kaggen, L., Campbell-Meiklejohn, D., \& Van Bavel, J. J. (2018). Amygdala structure and the tendency to regard the social system as legitimate and desirable. Nature Human Behaviour, 2(2), 133-138.

Ondish, P., \& Stern, C. (2018). Liberals possess more national consensus on political attitudes in the United States: An examination across 40 years. Social Psychological and Personality Science, 9, 935-943.

Onraet, E., Dhont, K., \& Van Hiel, A. (2014). The relationships between internal and external threats and right-wing attitudes: A three-wave longitudinal study. Personality and Social Psychology Bulletin, 40, 712-725.

Onsager, L. (1944). Crystal statistics. I. A two-dimensional model with an order-disorder transition. Physical Review, 65, 117-149. 
Osborne, D., \& Sibley, C. G. (2020). Does Openness to Experience predict changes in conservatism? A nine-wave longitudinal investigation into the personality roots to ideology. Journal of Research in Personality, 87, 103979.

Pedersen, T. L. (2019). patchwork: The composer of plots. R package version 1.0.0. https://CRAN.R-project.org/package=patchwork

Pedersen, T. L. (2020). ggraph: An implementation of grammar of graphics for graphs and networks. R package version 2.0.2 https://CRAN.R-project.org/package=ggraph

Peffley, M., \& Hurwitz, J. (1992). International events and foreign policy beliefs: Public response to changing Soviet-US relations. American Journal of Political Science, 431-461.

Phoenix, D. L. (2019). The Anger Gap: How Race Shapes Emotion in Politics. Cambridge University Press.

Pittinsky, T. L., Shih, M., \& Ambady, N. (1999). Identity adaptiveness: Affect across multiple identities. Journal of Social Issues, 55, 503-518.

Pomerantz, E. M., Chaiken, S., \& Tordesillas, R. S. (1995). Attitude strength and resistance processes. Journal of Personality and Social Psychology, 69, 408-419.

Putnam, R. D., Leonardi, R., \& Nanetti, R. Y. (1979). Attitude stability among Italian elites. American Journal of Political Science, 463-494.

R Core Team (2020). R: A language and environment for statistical computing. R Foundation for Statistical Computing, Vienna, Austria. https://www.R-project.org/.

Read, S. J., \& Monroe, B. M. (2019). Modeling cognitive dissonance as a parallel constraint satisfaction network with learning. In E. Harmon-Jones (Ed.), Cognitive dissonance: Reexamining a pivotal theory in psychology (p. 197-226). American Psychological Association. 
Read, S. J., Vanman, E. J., \& Miller, L. C. (1997). Connectionism, parallel constraint satisfaction processes, and gestalt principles:(Re) introducing cognitive dynamics to social psychology. Personality and Social Psychology Review, 1, 26-53.

Rekker, R., Keijsers, L., Branje, S., \& Meeus, W. (2015). Political attitudes in adolescence and emerging adulthood: Developmental changes in mean level, polarization, rank-order stability, and correlates. Journal of Adolescence, 41, 136-147.

Rekker, R., Keijsers, L., Branje, S., \& Meeus, W. (2017). The dynamics of political identity and issue attitudes in adolescence and early adulthood. Electoral Studies, 46, 101-111.

Rhodes, N., \& Wood, W. (1992). Self-esteem and intelligence affect influenceability: The mediating role of message reception. Psychological Bulletin, 111, 156-171.

Robinaugh, D., Haslbeck, J. M. B., Ryan, O., Fried, E. I., \& Waldorp, L. (2020). Invisible hands and fine calipers: A call to use formal theory as a toolkit for theory construction.

\section{https://doi.org/10.31234/osf.io/ugz7y}

Shultz, T. R., \& Lepper, M. R. (1996). Cognitive dissonance reduction as constraint satisfaction. Psychological Review, 103, 219-240.

Schuman, H., \& Presser, S. (1980). Public opinion and public ignorance: The fine line between attitudes and nonattitudes. American Journal of Sociology, 85, 1214-1225.

Schwarz, N. (2007). Attitude construction: Evaluation in context. Social Cognition, 25, 638-656.

Schweighofer, S., Schweitzer, F., \& Garcia, D., (2020). Weighted balance model of opinion hyperpolarization. Journal of Artificial Societies and Social Simulation, 131, $10.18564 /$ jasss.4306

Slothuus, R. (2016). Assessing the influence of political parties on public opinion: The challenge from pretreatment effects. Political Communication, 33, 302-327. 
Song, H., Lewis Jr, N. A., Ballew, M. T., Bravo, M., Davydova, J., Gao, H. O., ... \& RomeroCanyas, R. (2020). What counts as an "environmental” issue? Differences in issue conceptualization by race, ethnicity, and socioeconomic status. Journal of Environmental Psychology, 101404.

Stolier, R. M., Hehman, E., \& Freeman, J. B. (2020). Trait knowledge forms a common structure across social cognition. Nature Human Behaviour, 4, 361-371.

Tappin, B. M. (2020). Estimating the between-issue variation in party elite cue effects. PsyArXiv, https://doi.org/10.31234/osf.io/p48zb

Thagard, P. (2006). Hot thought: Mechanisms and applications of emotional cognition. Cambridge, MA: MIT Press.

Thagard, P. (2010). EMPATHICA: A computer support system with visual representations for cognitive-affective mapping. In K. McGregor (Ed.), Proceedings of the workshop on visual reasoning and representation (pp. 79-81). Menlo Park, CA: AAAI Press.

Thagard, P., \& Verbeurgt, K. (1998). Coherence as constraint satisfaction. Cognitive Science, 22, $1-24$.

Turner-Zwinkels, F. M., Sibley, C. G., Johnson, B. B., \& Brandt, M. J. (in press). Conservatives moral foundations are more densely connected than liberals' moral foundations. Personality and Social Psychology Bulletin.

Van Laar, C., Levin, S., Sinclair, S., \& Sidanius, J. (2005). The effect of university roommate contact on ethnic attitudes and behavior. Journal of Experimental Social Psychology, 41, $329-345$. 
Visser, P. S., \& Mirabile, R. R. (2004). Attitudes in the social context: the impact of social network composition on individual-level attitude strength. Journal of Personality and Social Psychology, 87, 779-795.

Washburn, A. N., \& Skitka, L. J. (2018). Science denial across the political divide: Liberals and conservatives are similarly motivated to deny attitude-inconsistent science. Social Psychological and Personality Science, 9, 972-980.

Wickham et al., (2019). Welcome to the tidyverse. Journal of Open Source Software, 4, 1686, https://doi.org/10.21105/joss.01686.

Xu, X., Plaks, J. E., \& Peterson, J. B. (2016). From dispositions to goals to ideology: Toward a synthesis of personality and social psychological approaches to political orientation. Social and Personality Psychology Compass, 10, 267-280.

Yin, J., and Li, H. (2011). A sparse conditional gaussian graphical model for analysis of genetical genomics data. The Annals of Applied Statistics, 5, 2630-2650.

Zmigrod, L., Rentfrow, P. J., \& Robbins, T. W. (2018). Cognitive underpinnings of nationalistic ideology in the context of Brexit. Proceedings of the National Academy of Sciences, 115, E4532-E4540.

Zorn, C., \& Bowie, J. B. (2010). Ideological influences on decision making in the federal judicial hierarchy: An empirical assessment. The Journal of Politics, 72, 1212-1221. 